\title{
Insulin-Like Growth Factor-1 Signaling in Lung Development and Inflammatory Lung Diseases
}

\author{
Zheng Wang $\left(\mathbb{D},{ }^{1}\right.$ Wenting Li ${ }^{D},{ }^{2}$ Qiongya Guo, ${ }^{3}$ Yuming Wang, \\ Lijun Ma, ${ }^{1}$ and Xiaoju Zhang $\mathbb{1}^{1}$ \\ ${ }^{1}$ Department of Respiratory and Critical Medicine, Zhengzhou University People's Hospital, Zhengzhou 450003, China \\ ${ }^{2}$ Department of Infectious Diseases, Anhui Provincial Hospital, Hefei 230001, China \\ ${ }^{3}$ Department of Digestive Diseases, Zhengzhou University People's Hospital, Zhengzhou 450003, China \\ ${ }^{4}$ Medical Research Center, Zhengzhou University People’s Hospital, Zhengzhou 450003, China
}

Correspondence should be addressed to Xiaoju Zhang; zhangxiaoju1010@163.com

Received 14 January 2018; Accepted 6 March 2018; Published 19 June 2018

Academic Editor: Nikolaos Siafakas

Copyright (c) 2018 Zheng Wang et al. This is an open access article distributed under the Creative Commons Attribution License, which permits unrestricted use, distribution, and reproduction in any medium, provided the original work is properly cited.

\begin{abstract}
Insulin-like growth factor-1 (IGF-1) was firstly identified as a hormone that mediates the biological effects of growth hormone. Accumulating data have indicated the role of IGF-1 signaling pathway in lung development and diseases such as congenital disorders, cancers, inflammation, and fibrosis. IGF-1 signaling modulates the development and differentiation of many types of lung cells, including airway basal cells, club cells, alveolar epithelial cells, and fibroblasts. IGF-1 signaling deficiency results in alveolar hyperplasia in humans and disrupted lung architecture in animal models. The components of IGF-1 signaling pathways are potentiated as biomarkers as they are dysregulated locally or systemically in lung diseases, whereas data may be inconsistent or even paradoxical among different studies. The usage of IGF-1-based therapeutic agents urges for more researches in developmental disorders and inflammatory lung diseases, as the majority of current data are collected from limited number of animal experiments and are generally less exuberant than those in lung cancer. Elucidation of these questions by further bench-to-bedside researches may provide us with rational clinical diagnostic approaches and agents concerning IGF-1 signaling in lung diseases.
\end{abstract}

\section{Introduction}

Insulin-like growth factors (IGFs) are produced mainly by the liver cells in response to pituitary hormones and form a feedback signaling loop with pituitary, liver, and growth hormone-releasing hormone release by the hypothalamus $[1,2]$. The activity of IGFs is approximately $1 \%$ that of insulin with respect to the metabolism of glucose, lipid, and protein. IGFs also promote differentiation of myoblastic or osteoblastic tissues into muscle and bone [3]. In addition to its role as a mediator in metabolism, IGF-1 is also implicated in developmental disorders, a variety of diseases other than metabolic disorders, or cancers. Immunological and genetic analyses have affirmed the expression of IGF-1 signaling components in cells from the normal lung tissue, including airway cells, lung parenchymal cells, smooth muscle cells, lung fibroblasts, and alveolar macrophages [4]. Recent researches redefine the previously recognized role of IGF-1 signaling in lung development and diseases, such as congenital disorders, cancers, inflammation, and fibrosis [5]. Abnormal IGF-1/IGF-1R signaling has been extensively studied in lung cancer that mediates oncogenesis, progression, metastasis, resistance to chemotherapy, or tyrosine kinase inhibitors (TKIs) [6]. The role of IGF-1/IGF-1R signaling abnormalities in lung cancer has been extensively reviewed elsewhere [2, 7-11]. Clinical trials have been finished or just begun to investigate the safety and efficacy of antibodies against IGF1 signaling in lung cancer [12-16]. The roles of IGF-1 signaling are also documented in patients with pneumothorax and alveolar rhabdomyosarcoma (ARMS), in animal models of pulmonary artery hypertension and postpneumonectomy lung regeneration $[5,17-19]$. In this review, we focus mainly on the roles of IGF-1 signaling in lung development and inflammatory diseases, as will be discussed in detail below. 


\section{IGF Signaling Pathway}

IGF signaling pathway is composed of three ligands (IGF-1, IGF-2, and insulin), three receptors [IGF-1 receptor (IGF-1R), IGF-2R, and insulin receptor (IR)], and a superfamily of six IGF binding proteins (IGFBPs 1-6) [20]. Insulin-like growth factor-1 (IGF-1) and IGF-2 are the only two members of IGFs identified hitherto. IGFs were firstly discovered by Salmon Jr. and Daughaday as single chain polypeptide hormones in their pursuit for mediators of the activity of growth hormone in 1957 [21]. IGF-1 and IGF-2 share 50\% homology, as well as some functions with insulin in regulating metabolism and growth. IGF-2 (also known as IGF-II or somatomedin A) is a 67-amino-acid peptide, and combination of IGF-2 with IGF-2R has not been found to associate with intracellular signaling. IGF-1 (also known as IGF-I or somatomedin C) is a $7.5 \mathrm{kDa}$ peptide that has 70 -amino-acid residues and four domains. IGF-1 gene is located on the long arm of chromosome $12(12 \mathrm{q} 23.2)$ and consists of 6 exons. The prototype of IGF-1 protein (pro-IGF-1) contains a C-terminal peptide that is proteolytically processed in the Golgi apparatus before secretion. IGF-1 gene splicing generates three splice isoforms, IGF-1Ea, IGF-1Eb, and IGF-1Ec. The functional difference among these isoforms has not been extensively analyzed in other cells and organs [22].

IGF-1, IGF-2, or insulin binds with different receptors or the receptor hybrids [23]. Alternative splicing of exon 11 gives rise to two splice variant isoforms of IR, IRA, and IRB, which may form IGF-1R/IR heterodimer with IGF-1R. Although IGF-1 may also combines with IRA or IGF-1R/IRA dimer, it combines with IGF-1R in most situations. IGF-1R is a type 2 tyrosine kinase transmembrane receptor that is normally found as a heterotetramer with two extracellular $\alpha$ and two membrane-spanning $\beta$ subunits [23, 24]. Ligands bind to the $\alpha$ subunit and activate the intrinsic tyrosine kinase activity of the $\beta$ subunit, which further binds and activates insulin receptor substrates (IRS) and Shc. Phosphorylation of IRS1 or IRS2 further activates the PI3K-Akt-mTOR signaling pathway via binding to $\mathrm{p} 85$ regulatory subunit of PI3K. Shc interacts with the growth factor receptor bound protein 2 (GRB2) and son-of-sevenless (SOS) to activate RAS, RAF, and the ERK/MAPK signaling pathway. IRS2 may regulate cellular motility by modulation of integrin expression possibly via RHOA, focal adhesion kinase (FAK), and Rho-kinase (ROCK) [23, 24]. GSK-3, IKK $\alpha$, Foxhead, FOXO, TSC1/2, BAD, caspase-9, Bcl-2, cyclinD1 are downstreaming IGF1/PI3K/Akt signaling, which are essential for metabolism, cell cycle, apoptosis, Wnt, and NF- $\kappa \mathrm{B}$ signaling activation. MAPK signaling pathway is also the key controller of cell fate that includes cell adhesion, proliferation, apoptosis, and survival $[20,23,24]$. The IGF-1 signaling pathway is depicted in Figure 1.

IGFBPs bind with high affinity with IGF-1 or IGF-2 and less affinity with insulin. Approximately 98\% of IGF-1 in the body fluid is bound to one of six IGFBPs, which may prolong the half-life of circulating IGF-1. IGFBPs may inhibit or promote IGF-1/IGF-1R signaling activities, depending on the type of IGFBPs, organs, and cells [25]. IGFBPs may also exert biological functions independent of IGF ligands and receptors [26]. Regulation of IGF-1/IGF-1R signaling may happen at the posttranscriptional level by mechanisms involving RNA stabilization and protein acetylation [27-29]. Noncoding RNAs also mediate the bioactivity of IGF-1 and IGF-1R [30]. Expressions of IGF-1, IGF-1R, and PI3K, as well as phosphorylation of AKT and FoxO3a, are inhibited by miR-470, miR-669b, or miR-681 [30]. There lies extensive crosstalk between IGF-1 and other signaling pathways that control cell physiology, such as insulin, integrin, Wnt, and epidermal growth factor receptor (EGFR) signaling pathways $[1,7,8,11,31,32]$.

\section{IGF-1 Signaling in Lung Development}

3.1. Congenital IGF-1/IGF-1R Signaling Abnormalities and Lung Development. Individuals with congenital IGF-1 signaling deficiencies are born predominantly with metabolic and systemic developmental alterations, less with lung disorders $[33,34]$. Lung hypoplasia may manifest in patients losing one IGF-1R gene copy for chromosome 15 deletion, along with other disorders such as intrauterine growth retardation (IUGR), microcephaly, abnormal face and ears, micrognathia, highly arched palate, renal abnormalities, failure to thrive, developmental delay, and mental retardation [35]. Mutations of IGF-1 gene result in decreased serum levels or binding affinity of IGF-1; patients are characterized by severe intrauterine growth retardation, microcephaly, postnatal growth failure, severe psychomotor retardation, sensorineural deafness, and mild dysmorphic features [36-38]. Primary growth hormone insensitivity (Laron syndrome) is the most common and prototypical condition within the primary IGF deficiency (PIGFD) category, which is characterized by extremely low serum IGF-1 levels that may require IGF-1 treatment [39]. Patients with Laron syndrome have abnormal phenotype of the growth factor receptor (mutated or inactivated), who demonstrate growth and organic development retardation, short stature, delayed bone age, and reduced exercise capacity, but their lung function is normal, and none of lung injury or bronchopulmonary dysplasia has been reported [40]. Acromegaly may present with high levels of growth hormone and varying levels of IGF-1 and similar lung structure and functions compared with health controls, and none of the lung functional, radiological, and biological findings correlated with IGF-1 levels [41, 42].

Interestingly, the velocity of intrauterine and postnatal growth is correlated with levels of IGF-1. Prenatal tracheal occlusion or ligation, a well-documented stimulator of fetal lung growth, is accompanied with an increase in expression of IGF-1 within rat lungs [43]. Neonatal cord plasma levels of IGF-1 and IGFBP-3 are associated with fetal growth and possibly fetal lung growth and are decreased in the babies of mothers who had smoked $[44,45]$. Prenatally parental cigarette smoking in female mice reduces the mRNA levels of Igf1 and Igflr and gives rise to $\mathrm{CpG}$-site specific methylation changes in Igflr [46]. Decreased level of IGF-1 is responsible for hypoxia-induced abnormal development and chronic inflammation of the lungs in postnatal rats [47]. This might be supported by large-scale epidemiological studies, which show the positive linear associations between plasma IGF-1 and 


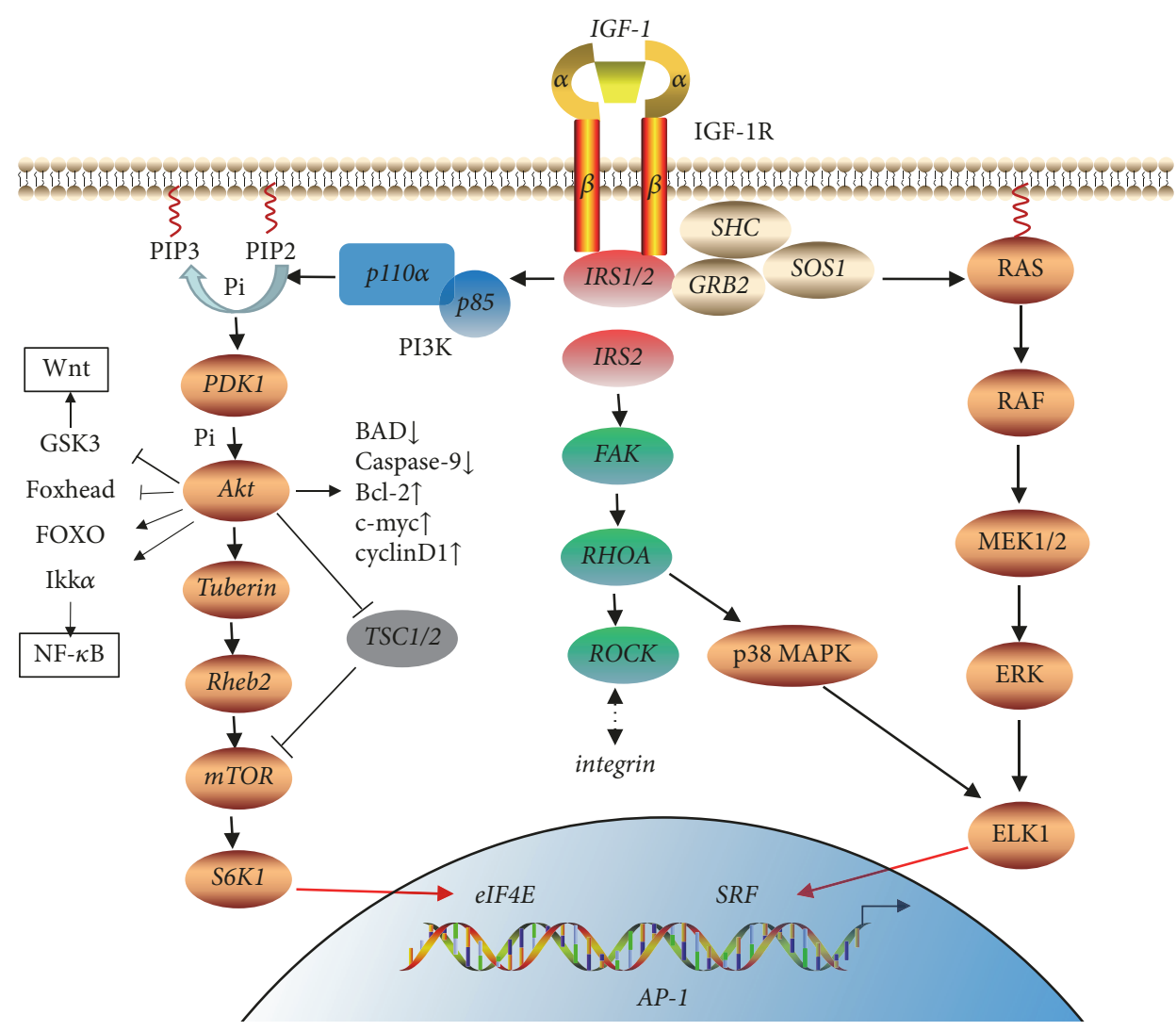

FIGURE 1: IGF signaling pathway. IGF-1 binds with IGF-1R and activates its intracellular kinase activity, which activates insulin receptor substrates (IRS-1 and IRS-2). IRS-1 and IRS-2 further regulate the transcription of downstream genes as well as cell physiology by activating RAS/Raf/MAPK and PI3K/Akt/mTOR signaling pathways. IRS-2 also activates Rho-kinase (ROCK) and p38 MAPK via focal adhesion kinase (FAK) and crosstalk with Wnt, NF- $\kappa$ B, and integrin signaling pathways.

lung function, most evidently in men and in women above 50 years old $[48,49]$.

\subsection{IGF-1 Signaling Deficiency Models. IGF-1 and IGF-1R} are widely distributed throughout the neonatal rodent lungs. The impact on the lung development is more prominent in animals than in humans of IGF-1 or IGF-1R deficiency [1]. Studies with animal models suggest that IGF-1 modulates the development and differentiation of many types of lung cells, including airway basal cells, club cells, alveolar epithelial cells, and fibroblasts. The mechanisms involved remain largely unknown, but it is likely that autocrine and paracrine effects are involved, possibly via downstream and interacting signaling pathways of IGF-1.

Plasma IGF-1 is elevated or decreased in growth hormone transgenic or growth hormone receptor knockout mice. Except for that mice are less viable, lungs of survivors have well-developed bronchi, bronchioles with Clara cells and alveoli, and no signs of inflammation [50, 51]. Igf1 transgene mice show alveolar hyperplasia [52]. Prenatal Igf1-/- mutant mice are less viable for lethal neonatal respiratory distress, which displayed immature and delayed distal pulmonary organogenesis as manifested by severe lung hypoplasia, thickened mesenchyme, diffuse extracellular matrix deposition, thinner smooth muscles, and dilated blood vessels [53].
Similarly, IGF-1R-/- (knockout) embryos display active cell proliferation and apoptosis, severe lung hypoplasia, and markedly underdeveloped diaphragms and could hardly survive lethal neonatal respiratory distress [53-55]. In contrast, IGF-1Rneo/- mice that express $22 \%$ of normal IGF-1R levels are viable and have normal lung histomorphometric characteristics and normal breathing response to hypercapnia [55]. The discrepancies between IGF-1 and IGF-1R deficiency may be attributed to the universality of IGF-1R in inducing signaling or different compensatory responses [56]. Subsequent alterations of RNA transcriptome in IGF-1 knockout include genes related to vascularization, morphogenesis, cellular growth, immunological reactions, and MAPK, Wnt, and cell adhesion pathways [57]. Notably, MAPK/ERK2 is activated while Egrl and Ctgf are inactivated [57]. These genes and signaling pathways may serve as mediators downstreaming IGF-1 signaling in epithelium maturation during prenatal lung development [57].

Human airway basal cells (BC) function as stem/progenitor cells of the human airway epithelium, capable of differentiating into ciliated and secretory cells during turnover and repair. Studies have revealed that IGF-1 signaling mediates the developmental fate of basal cell differentiation, possibly via FoxO-mediated p63 inhibition [58]. Knockout of histone methyltransferase Ezh2 derepresses IGF-1 signaling, which 
results in reduced lung volume, perturbed airway lineage specification, and a defect in alveoli formation in mice [54]. IGF-1 signaling ex vivo in wild-type lungs induces dilatation of airways, basal cell differentiation, and expression of Krt5, Krt14, and Trp63 mRNA [59]. These results suggest that repression of Igf1 expression by Ezh2 in lung epithelial cells is likely to be a crucial process for controlling basal cell fate determination and maintaining a proper control of lineage specification during embryonic lung morphogenesis. The role of IGF-1 signaling in basal cell differentiation is further indicated in a coculture system of human airway basal cells and lung microvasculature endothelial cells. Differentiation of basal cells is stimulated by coculture via activation of IGF1R-mediated Akt and ERK1/2 signaling and is suppressed by siRNA-mediated knockdown of IGF-1R in basal cells [60].

IGF-1R deficiency disturbed airway epithelial differentiation in adult mice and enhanced proliferation and altered morphology in distal airway club cells [61]. These morphological alterations are accompanied by increased expression in epithelial cell precursor-specific genes and reduced expression of Clara cell secretory protein (CCSP) [61]. The expression of IGF-1R mRNA and JNK protein is elevated, and ERK signaling is repressed after club cell ablation with naphthalene challenge [61]. Blockage of IGF-1, or of IGF-1R with a truncated soluble IGF-1R, reduces lung tissue fraction, lung procollagen I and elastin fiber production, total lung cell and secondary crest cell DNA synthesis, and lung small vessel density and impairs alveologenesis, as assessed by secondary crest formation and mean linear intercepts [62]. The expression of IGF-1 mRNA is upregulated during the transformation of cultured alveolar type II (ATII) cells to alveolar type I (ATI) cells [63], and addition of antibodies against IGF-1 or IGF-1R inhibits ATII cell proliferation and trans-differentiation to some extent [64]. Recombinant IGF1 promotes the differentiation of ATII to ATI, which is abrogated by a IGF-1R blocker, and is accompanied by activation of Wnt5a, protein kinase $\mathrm{C}$, and $\beta$-catenin, suggesting the involvement of Wnt5a-dependent activation of Wnt/Frizzled signaling pathway [63].

IGF-1 collaborates with leukemia inhibitory factor (LIF) in lung alveolar epithelium and vascular maturation [65]. IGF-1-deficient mouse embryos display a higher proportion of type II pneumocytes, less differentiated type I pneumocytes, and failure in alveolar capillary remodeling compared to wild-type mice [65]. Lif/Igf1 double knockout lungs show aggravated pulmonary hypoplasia, lower airway volume, increased proliferation, collapsed alveoli that are lined by ATII cells, and elevated levels of ERK1/2 activation [65]. Fibroblast growth factor-stimulated IGF-1 signaling may also contribute to alveolar elastogenesis in a paracrine manner [66].

3.3. IGF-1 Signaling in Bronchopulmonary Dysplasia (BPD). Bronchopulmonary dysplasia (BPD), characterized by decreased alveolar septation and/or lung inflammations, is the most common chronic lung sequelae that occurs in survivors of very preterm birth or of intensive care after birth [67]. Hyperoxia-disturbed IGF-1 signaling is believed to play an important role in BPD [67,68]. Serum levels of IGF-1 are significantly decreased and low serum IGF-1 levels at 33 weeks' postmenstrual age predict high risk for developing BPD $[69,70]$. However, the expression of IGF-1 in epithelial lining fluid, epithelial cells, and peribronchial myofibroblasts was increased in BPD [71, 72]. This is further identified in hyperoxia-stimulated ex vivo neonatal rat lung model, as IGF-1 staining is most abundant in airway and alveolar epithelial cells and cell proliferation is accompanied by excessive IGF-1 mRNA and protein expression and could be inhibited by IGF-1 antibody [73].

Hyperoxia inactivates IGF-1/IGF-1R signaling by attenuating their specific binding affinity in neonatal lungs or fetal lung distal epithelial cells, which further impairs lung cell proliferation, secondary crest formation, and alveologenesis [74]. The proteins and mRNA of IGF-1 and IGF-1R increase during hyperoxia lung injury and are highly abundant in ATII cells. Among IGFBPs, IGFBP-2, IGFBP-3, and IGFBP5 mRNA increased during hyperoxia-induced injury, and IGFBP-5 mRNA is also elevated during the recovery phase [74]. Hyperoxia significantly increases IGF-1 levels in BALF and mouse lung lysates, as well as IGF-1R-positive neutrophils in peripheral blood and in BALF [75]. IGF-1 induced a dosedependent chemotaxis of polymorphonuclear cells to the alveolar space, which is decreased by systemic pretreatment of an IGF-1R antibody in hyperoxia-injured mice [75]. The ratio of epithelial lining fluids concentrations of IGF-1 to PAPP-A (pregnancy-associated plasma protein-A), a metalloproteinase that dissociates IGFBPs, is increased and associated with lung injury and malformation in BPD [76]. Another research identifies the role and therapeutic potentials of miR489-mediated IGF-1 expression in hyperoxia-exposed lungs or BPD [77]. MiR-489 is reduced in BPD infants and in a mice model of hyperoxia-induced BPD, in which hyperoxia increases IGF-1 expression in mice lungs. Inhibition of miR489 permits alveolar septation to proceed. MiR- 489 is of epithelial origin and presents in exosomes, while its targets Igf1 and Tnc are produced by fibroblasts, suggesting the presence of paracrine effecting mechanisms [77]. Hyperoxia exposure can promote pneumocyte apoptosis and inhibit the expression of CCSP [78]. Intraperitoneal injection of recombinant human insulin-like growth factor-1 (rhIGF-1) alleviates pneumocyte apoptosis, restores CCSP expression, and removes the block of the formation of lung alveoli in hyperoxia-exposed rats, which provides rationale for clinical application of rhIGF-1 in prevention and treatment of BPD [78]. Decrease in IGF-1R expression protects mice against $90 \%$ oxygen-induced lung injury, as demonstrated by less edema, vascular extravasation, and respiratory failure than control mice lungs [79]. In a clinical trial investigating the efficacy of rhIGF-I/rhIGFBP-3 in prevention of retinopathy of prematurity (ROP) in premature infants, the occurrence of BPD serves as a secondary outcome [80]. The rhIGFI/rhIGFBP-3 seems to reduce the occurrence of BPD as compared with standard care: $21.3 \%$ (10 in 47 infants) versus $44.9 \%$ (22 in 49 infants) [80]. These findings in all demonstrate the therapeutic potentials of IGF-1 in BPD, which possibly restores hyperoxia-disrupted regeneration and differentiation of alveolar epithelium. 


\section{IGF-1 in Fibrotic Lung Diseases}

4.1. Evidences of IGF-1 Signaling in Fibrotic Lung Diseases. Upregulated IGF-1 expression and/or signaling is present in (1) patients with idiopathic fibrotic lung diseases, such as idiopathic pulmonary fibrosis (IPF) and late-stage sarcoidosis [81], (2) patients with secondary fibrosis, such as silicosis, pneumoconiosis, drug-induced pulmonary fibrosis, mustard gas-induced pulmonary fibrosis, systemic sclerosis-related interstitial lung disease, and rheumatoid arthritis-related interstitial lung disease [82-89], and (3) animal models of lung fibrosis induced by bleomycin, paraquat or silica challenge, and radiation [90-92]. The complexity of IGF1 signaling is evidenced in fibrotic process, as it may be time- and space-dependent. The expression of IGF-1 mRNA is downregulated in lung tissues from patients with idiopathic pulmonary fibrosis (IPF) or sarcoidosis, while basal or TGF$\beta 1$-stimulated IGF-1 expression is higher in fibroblasts collected from IPF or fibrotic (Phase III or IV) sarcoidosis than health controls $[93,94]$. An increase of IGF-1 and IGF-1R expression in alveolar macrophages (AM) and ATII cells is observed in IPF and sarcoidosis [95]. In lung tissues with late-stage IPF and those from normal controls, only alveolar macrophages contain IGF-1 protein [95]. IGF-1 protein is localized and expressed in alveolar macrophages, mononuclear phagocytes, fibroblasts, ATII cells, vascular endothelial cells, and vascular smooth muscle cells in lung tissues with early-stage IPF [96]. Another similar study shows the localization of IGF-1 in AMs, interstitial macrophages, ATI and ATII, and ciliated columnar epithelial cells, as compared to healthy controls in that IGF-1 is expressed mainly in AMs of IPF patients [96]. Microarray data also show increased IGF-1 gene expression in IPF patients [97]. The levels of IGF-1 are elevated in BALF collected from systemic sclerosis patients as compared with control subjects and increase more in systemic sclerosis patients with abnormal computed tomography, which stimulates fibroblast proliferation [85].

4.2. IGF-1 Signaling Activates Lung Fibroblasts and Myofibroblasts. Although the exact role and regulation of IGF-1 signaling in pulmonary fibrosis are awaiting for elucidation, previous studies have given some clues. IGF-1 activates lung fibroblasts, in preventing apoptosis, stimulating the proliferation, and enhancing elastin and collagen production $[98,99]$. IGF-1 stimulates the proliferation and differentiation of lung fibroblasts into myofibroblasts, increases collagen synthesis, and protects myofibroblasts from apoptosis and thus may directly or indirectly increase the overall quantity of myofibroblast-produced extracellular matrix in the lungs $[100,101]$. IGF-1 requires IGF-1R to prevent mouse embryo fibroblasts from TNF- $\alpha$ - or ECM detachment-induced apoptosis in vitro $[102,103]$. Blockade of the IGF-1/IGF-1R pathway by an IGF-1R antibody induces fibroblast apoptosis and subsequent resolution of pulmonary fibrosis [104]. IGF-1 activates and increases migration of lung fibroblast, possibly via IRS2/PI3K/Akt signaling pathway [104]. The antiapoptotic effect of IGF-1 in fibroblasts might be mediated by ras, FOS, EGR-1, EGR-2, PI3K/Akt, and/or MAPK signaling activation and could be blocked by an antibody or siRNA targeting IGF-1R [99, 103, 105]. Further microarray analysis in IGF-1-stimulated mouse NIH-3T3 fibroblasts shows elevated expressions of EGR-1, Twist, Jun, integrin $\alpha 5$, IL-4R $\alpha$, and IL$3 \mathrm{R} \alpha$ genes, which may control cell proliferation, apoptosis, mitogenesis, and differentiation [106]. IGF-1 secretion from lung epithelium is promoted by downregulation of miR-130b$3 p$ in IPF, which induces collagen I expression and enhanced the proliferation and migration ability of fibroblast [107].

4.3. IGF-1 Signaling Induces EMT of Alveolar Epithelial Cells. IGF-1 may induce epithelial-mesenchymal transition (EMT) of ATII cells, an important process forming fibroblast-like, ECM-producing cells in pulmonary fibrosis [108]. IGF-1 and IGFBP-5 expressions are significantly reduced in ATII cells in a rat model of bleomycin-induced pulmonary fibrosis [109]. This is accompanied by an increase in surface protein $\mathrm{C}$ (SPC) and $\alpha$-SMA expression and their colocalization in ATII cells, which suggests the involvement of IGF-1 signaling in EMT of ATII cells during the process of lung injury and fibrosis [109]. IGF-1 induces MMP-2 and MMP-9 expression in alveolar epithelial cells through ERK signaling [110]. There is crosstalk between IGF-1 and integrin signaling pathways, which modulates cell physiology such as growth, adhesion, migration, and extracellular matrix (ECM) production [32, $111,112]$. In a mice model of bleomycin-induced pulmonary fibrosis, three miRNAs and IGFBP3 are decreased, while IGF-1, IGFBP-5, and 8 miRNAs are increased [113]. Further bioinformatic analysis reveals IGF-1 signaling as among the targets of the differentially expressed miRNAs [113]. Fra2/AP-1 contribute to pulmonary fibrosis in IPF and animal models of pulmonary fibrosis, possibly through activation of profibrotic signals, including IGF-1 [114].

Expression of IGFBPs is elevated in lung (IGFBP-3, IGFBP-5) and in serum levels (IGFBP-1, IGFBP-2) in IPF patients [113, 115-117]. IGFBP-2 is associated with proliferation of lung alveolar epithelial cells [118] and is highly expressed in sputum of IPF patients [119]. Syndecan-2 and tenascin, profibrotic genes that are increased in lung tissues of patients with systemic sclerosis or IPF, are induced in fibroblasts by TGF- $\beta$ in an IGFBP-3-dependent manner or by IGFBP-3 alone $[120,121]$. IGFBP-5 gives rise to EMT in lung epithelial cells and stimulates lung fibroblasts to generate ECM $[115,122,123]$. These effects are mediated through IGF-1-dependent ERK1/2 activation or induced by binding of IGFBP-5 with individual ECM components including collagen, vitronectin, heparin, laminin, thrombospondin-1, plasminogen activator inhibitor-1, and osteopontin [124, 125].

4.4. IGF-1 and Alveolar Macrophages in Pulmonary Fibrosis. IGF-1 secreted by lung macrophages or ATII cells may act in a paracrine manner in alveolar compartment. IGF-1 released by alveolar macrophages (AMs) is elevated in BALF, which increases fibroblast mitogenic activity of sarcoidosis BALF that contributes to late-stage pulmonary fibrosis [126]. IGF-1 is released by quartz dust-exposed human macrophages as a result of phagocytosis in vitro, serving as a paracrine mitogen for human fibroblasts, ATII, and tracheobronchial epithelial cells, which is suggested to be involved in the epithelial repair and hyperplasia observed in silicosis [127, 128]. These 
stimulatory effects can be blocked by an IGF-1 antibody [128]. An IGF-1-dependent pathway is indicated for the stimulatory effect of rat ATII cells on type I collagen secretion by fibroblasts in the coculture system, which is blocked by an IGF-1 antibody [129].

As shown by Uh et al. in IPF patients, the number of IGF-1 positive interstitial macrophages correlates with the severity of collagen deposition and clinical impairment [96]. Mora et al. developed a mice model of progressive pulmonary fibrosis by infecting IFN- $\gamma$ R-deficient mice with the murine gamma-herpesvirus 68 [130]. The coexpression of IGF-1 and fibronectin is elevated in AMs, which suggests the possible existence of alternative activated macrophage (M2 macrophage) [130,131]. M2-polarization of macrophages could be induced by IL-4 and IGF-1 downstream signaling, including JNK and PI3K/AKT signaling pathways [132]. Alternatively activated macrophages secrete profibrotic growth factors including TGF- $\beta$, fibroblast growth factor (FGF), platelet-derived growth factor (PDGF $\alpha$ ), which stimulates proliferation, ECM production, and differentiation of fibroblasts into myofibroblasts [133].

4.5. Feedback Loops of IGF-1 Signaling in Pulmonary Fibrosis. There may also exist positive feedback of IGF-1 signaling in the molecular levels that promote pulmonary fibrosis. Lung cells including activated AMs express both IGF-1 and IGF-1R, providing an autocrine activation effect [134, 135]. The expression of IGF-1 is promoted in IGF-1-stimulated lung fibroblast cells [99]. Overexpression of IGF-1 could be further magnified by exogenous TGF- $\beta 1$ in fibroblasts recovered from BALF of IPF patients [92]. IL- 4 receptor $\alpha$ and Twist, which are well-recognized profibrotic signals, are listed in upregulated genes in IGF-1-stimulated mouse fibroblasts [105]. On the other side, expression of IGF-1 is inhibited by Th1 cytokine IFN- $\gamma$ and induced by Th2 cytokines IL4 and IL-13, while pulmonary fibrosis is a typical Th2 response that IL-4 and IL-13 predominate [136, 137]. IL-4induced, macrophage-derived IGF-1 protects myofibroblasts from apoptosis via Akt signaling, which may contribute to the persistence of myofibroblasts in the Th2-deviated environment of pulmonary fibrosis [138]. Interestingly, the relationship between IL-4 and IGF-1 is complicated, as IL4 pretreatment restrains IGF-1-stimulated mitogenesis by $60 \%$ in bovine fibroblasts via induction of IRS-2 phosphorylation and IL-4 receptor uses IRS-2 as its major substrate for tyrosine phosphorylation [139].

4.6. Evidences against IGF-1 as the Key Signaling Pathway in Pulmonary Fibrosis. Although abnormal IGF-1 signaling is implicated in human diseases and in animal models of lung fibrosis, there are also evidences suggesting that IGF-1 may not play a central role in the fibrotic process [140]. Adenoviral vector-mediated overexpression of IGF-1 in the mice lungs does not result in significant fibroblast or collagen accumulation featuring pulmonary fibrosis, but significant and prolonged inflammatory cell infiltration instead [141]. ATII cell-specific IGF-1 transgenic mice have normal lung pathology, cellularity of BALF, and total lung collagen content, as well as the extent of pulmonary inflammation or fibrosis compared with nontransgenic littermate controls [142]. Additionally, IGF-1 plus TGF- $\beta 1$ transgene expression synergistically increased lung inflammation and collagen deposition compared with active TGF- $\beta 1$ overexpression alone [143]. These data reveal that IGF-1 may not be able to initiate fibroproliferation on its own, but rather enhance pulmonary fibroproliferation in cooperation with TGF- $\beta 1$. Another study shows that TGF- $\beta 1$ but not IGF-1 increased $\alpha$-SMA promoter activity, and no synergistic effect was seen with IGF-1 and TGF- $\beta 1$ costimulation in mouse lung fibroblasts [144]. In addition, the role of IGF-1 in fibroblast activation may depend on the biomechanical properties of the ECM, as IGF-1 promotes $\alpha$-SMA expression only in soft substrates while it enhances expression of other myofibroblast markers such as Collal and Col3al in soft and stiff substrates [144]. Furthermore, chronic IGF-1 stimulation leads to mitochondrial dysfunction, decreased autophagy, and reduced cell viability in human fibroblasts in vitro [145]. The results altogether suggest that the profibrotic effect of IGF-1 depends on the time course of injury and repair as well as the properties of microenvironment and should be induced by convergence with TGF- $\beta 1$ or other profibrotic signals.

Despite these evidences, a recent study investigated the role of IGF-1R in experimental pulmonary fibrosis by exposing IGF-1R deficiency mice to bleomycin [146]. IGF$1 \mathrm{R}$ deficiency is associated with transcriptome changes, diminished Igf1 levels, and increased levels of Igfbp3, Igfbp5, Insr, and Foxol [146]. IGF-1R depletion improves mouse survival, reduces alveolar damage and HIF1A expression, protects against lung vascular fragility and permeability, and reduces lung inflammatory cell infiltration and bone marrow neutrophilopoiesis [146]. Cellular responses induced by IGF signaling pathway in pulmonary fibrosis are described in Figure 2.

\section{IGF in Acute Lung Injury (ALI) and Acute Respiratory Distress Syndrome (ARDS)}

ARDS, the most severe form of ALI, is one of the most fatal lung diseases [147]. IGF signaling was first identified as biomarkers for ALI and ARDS. In small case series, serum free IGF-1 level is significantly elevated in the early ALI/ARDS group compared to that in healthy controls and fibroproliferative ARDS group. Free IGF-1 levels in epithelial lining fluid, as well as lung IGF-1 mRNA expressions and IGF-1 immunoreactivity in lung biopsy specimens, are increased in fibroproliferative ARDS compared to those in healthy controls [148]. IGF-1 and IGF-1R immunoreactivity is enhanced in fibroproliferative ARDS and is seen in alveolar macrophages and epithelial cells lining the airways as well as in a variety of interstitial cells [148]. However, AMs collected from BALF of fibroproliferative ARDS are not elevated as compared with those of controls, which suggests lung cells other than AMs are the major source of IGF-1 expression in fibroproliferative ARDS [149].

The levels of IGF-1 and IGFBP-3 are elevated in atrisk patients and those with early ARDS, when epithelial damage and death occur, and decreased in late ARDS [150]. Antibody blockage of IGF-1R induces dose-dependent 


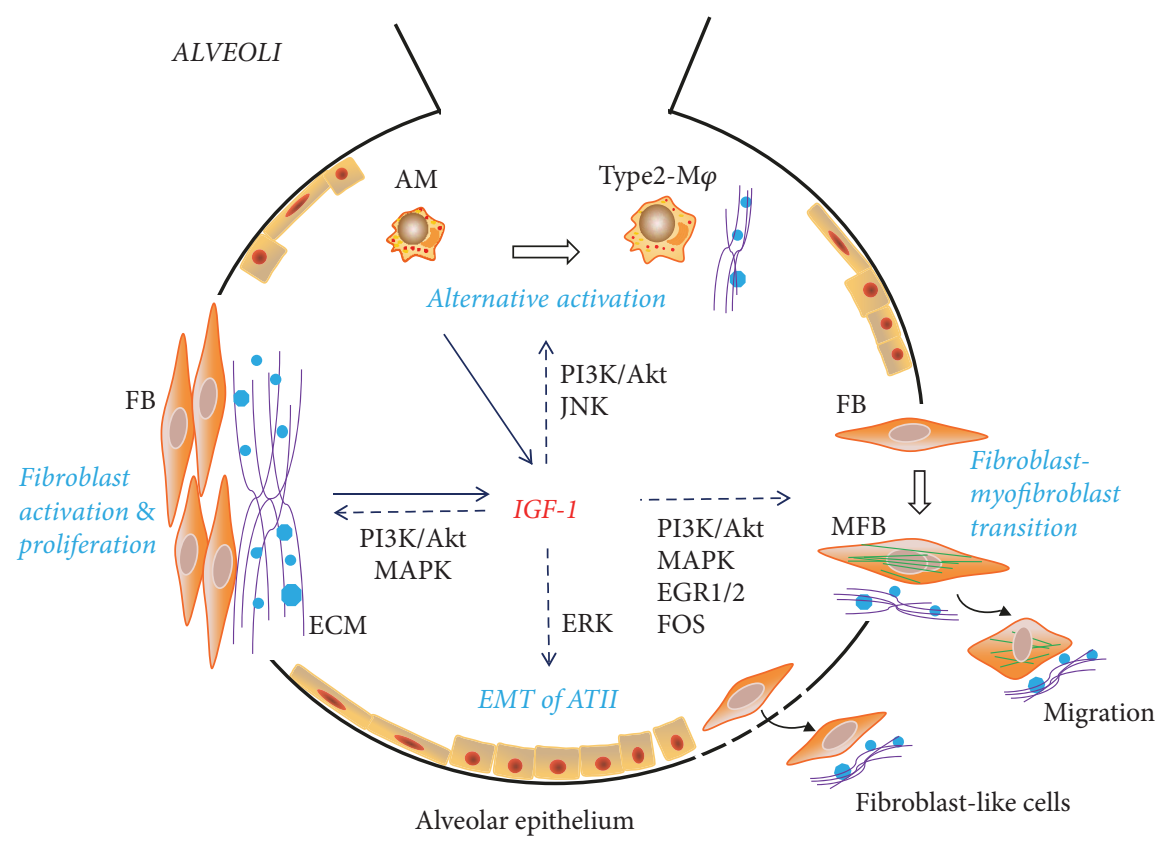

FIGURE 2: Cellular responses induced by IGF signaling pathway in pulmonary fibrosis. IGF-1 is produced by alveolar macrophages (AMs) and fibroblasts. IGF-1 activates fibroblast via PI3K/Akt and MAPK signaling and leads to fibroblast-myofibroblast transition via PI3K/Akt, MAPK, EGR1/2, and FOS signaling. Transition of type II alveolar epithelial cells to fibroblast-like cells is mediated by IGF-1-induced ERK activation. IGF-1 mediates alternative activation of alveolar macrophages, generating type 2-activated macrophages. Except for fibroblasts and myofibroblasts, EMT-generated fibroblast-like cells and alternative type 2-activated macrophages are all capable of producing extracellular matrix (ECM) and profibrotic signals.

apoptosis of primary human lung fibroblasts but not primary lung epithelial cells or human macrophage cells [150]. ARDS is strongly associated with IGF-1 and IGFBP-3 levels in critically ill patients [151]. A rs2854746 polymorphism is significantly associated with plasma IGFBP-3 [151]. According to a large prospective case-control study, baseline plasma levels of IGF-1 and IGFBP-3 are significantly lower in ARDS cases than controls [152]. Among ARDS cases, IGF-1 and IGFBP-3 levels were significantly lower in nonsurvivors than survivors, and both are negatively associated with hazard of 60-day mortality in multivariate models [152]. Dynamic bioinformatic assay revealed that plasma IGF-1 level is higher in day 1, but lower in day 3 in severe pneumonia-associated ARDS than that in severe pneumonia [153]. Plasma level of IGF-1R is higher in days 1,3 , and 7 in severe pneumoniaassociated ARDS than that in healthy controls [153]. Levels of IGFBP-4 and IGFBP-2 are also changed dynamically through the time course of ARDS, providing them the potential of being as a biomarker [153]. These inconsistent clinical data indicate the complexity of lung, muscle, and systemic inflammatory responses of ALI that may be timedependent, organ-dependent, and individualized and may reflect the status of growth hormone resistance in ARDS [152154]. In addition to extensive lung inflammation, aerosolized LPS in mice leads to increases in the numbers of airway epithelial cells and mucus cells and mucus production in a dose-dependent manner [155]. Hyperplastic epithelial cells are IGF-1-positive and expressing high levels of Bcl-2 and Muc5ac in this model [155]. IGF-1 knockdown suppresses $\mathrm{Bcl}-2$ expression in human and murine airway epithelial cells and Muc5ac in primary murine airway epithelial cells [155]. Intranasally LPS challenge in mice induces IGF-1, Bcl-2, IL1, and MUC5ac expression while it downregulates IGFBP-3 in laser-capture microdissected AECs by microarray analysis [156].

The production and absorption of alveolar edema in ALI and ARDS are mediated, respectively, by increased alveolar and vascular permeability and inactivation of epithelial sodium channel $(\mathrm{ENaC})$, which are both regulated by IGF-1 signaling $[157,158]$. Subcutaneous injection of recombinant human IGF-1 increases capillary permeability of the skin and the retina in healthy subjects [159]. IGF-1 improves the barrier properties of the aging microvascular endothelial cells in vitro and in ischemic mice brains [160]. IGF-1R knockout renders endothelial cells more prone to endothelial barrier dysfunction both in vivo and in vitro, possibly by disrupting the interaction between VE-protein tyrosine phosphatase and VE-cadherin [161]. IGF-1R signaling also activates vascular endothelial growth factor (VEGF) signaling via MAPK and has thus a protective effect in enhancing endothelial repair, regeneration, and vascularization $[162,163]$. Intraocular, but not systemic expression of IGF-1 increases IGF-1R content and signaling and led to accumulation of VEGF and increased retinal vessel paracellular permeability [164].

LPS challenge in alveolar epithelial cells significantly downregulates $\alpha \mathrm{ENaC}$ mRNA by reducing $\alpha \mathrm{ENaC}$ promoter activity via the ERK1/2 and p38 MAPK pathways [165]. IGF-1 signaling regulates the activity of Nedd4, which is the key modulator of ubiquitinylation and subsequent degradation of ENaC [166]. This effect is mediated by 
phosphorylation of Akt1 and activation of Sgk-1 in primary rat fetal alveolar epithelial cells [167]. The ATII-protective effect of IGF-1 is also recorded, as intracheal injection of recombinant adenoviruses 5 of IGF-1 (Ad5-IGF-1) protects ATII cells and prevents mice from acute lung injury induced by perfluoroisobutylene inhalation [168]. Mesenchymal stem cell- (MSC-) derived conditioned medium ameliorates lipopolysaccharide- (LPS-) induced lung injury, by attenuating lung inflammation and promoting a wound healing/anti-inflammatory M2 macrophage phenotype, possibly via paracrine mechanisms involving IGF-1 [169]. These data in sum suggest a pathological and a potentially therapeutic role of IGF-1 in ALI and ARDS.

\section{IGF in Asthma}

6.1. Abnormal IGF-1 Signaling in Asthma. As has been reviewed, IGF-1 signaling pathway and IGFBP-3 are of therapeutic significance in asthma [170]. Although prenatal parental cigarette smoking may alter fetal growth and IGF-1 signaling [44-46], it is noteworthy that prepubertal allergic boys typically present with normal serum levels of IGF-1 and IGFBP-3 [171]. Thus data are insufficient for reaching the conclusions that congenital or prenatal IGF-1 signaling abnormality contributes to the development of asthma. IGF-1 mRNA level is significantly elevated in endobronchial biopsies from asthma patients and is correlated with subepithelial fibrosis, which is partly reversed by inhaled beclomethasone dipropionate [172]. Being as the basis for asthma treatment, steroids appear to inactivate IGF-1/IGF-1R signaling indirectly or directly by downregulating the expression of IGF-1 and IGF-1R both locally and systemically $[173,174]$. Both dexamethasone and montelukast attenuate ovalbumin-induced asthmatic lung inflammation in guinea pigs, possibly via inhibition of IGF-1 and other proinflammatory signals [175]. Aerobic training, a recommended adjuvant treatment for asthmatic patients, reduces the expression of proinflammatory signals including IGF-1 and activation of peribronchial leukocytes, resulting in decreased airway inflammation and Th2 response in a mouse model of allergic asthma [176, 177]. In contrast, IGF-1 is among the proinflammatory mediators upregulated by creatine supplementation that exacerbates goblet cell proliferation and IL-5 and iNOS expression by epithelial cells in an asthma model $[178,179]$.

Genome-wide association study (GWAS) reveals that bronchodilator response in asthmatic children is associated with PAPPA2, which may cleave IGFBP-5 and regulate local IGF bioavailability $[180,181]$. Microarray analysis reveals that IGF-1 mRNA is elevated in lungs from ovalbumin-induced asthmatic model, which could be reduced by knockout of retinoid-related orphan receptor alpha $(\operatorname{ROR} \alpha)$ [182].

6.2. IGF-1 Signaling Activates Airway Smooth Muscle Cells in Asthma. IGF-1 stimulates mitogenesis of human airway smooth muscle (ASM) cells but not human fetal lung fibroblasts [183]. The production of granulocyte macrophage colony stimulating factor (GM-CSF), a recognized cytokine that maintains the inflammation and vascular leakage in asthma, is potentiated by IGF-1 in human ASM cells via p38 MAPK $[184,185]$. ASM cells express IGF-1, IGF-2, IGF receptors, IGFBP-3, and IGFBP-2 [186]. IGFBP-2 that is secreted into the conditioned medium by ASM cells blocks the IGF-induced ASM proliferation [187]. IGF-1 is associated with enhanced proliferation and hyperplasia of ASM cells and induces Rho-kinase-dependent sustained contraction of human ASM cell rings [188]. The mitogenic effect of IGF-1 is enhanced by leukotriene D4 (LTD4) [189]. The synergetic effect of IGF-1 and LTD4 in ASM proliferation is mediated by MMP-1, which is one of the IGFBP proteases, thus enhancing IGF-1 activity [190]. Airway tissues from asthmatic patients show that the expression and proteolytic activity of MMP-1 are significantly enhanced in ASM cells and that IGFBP-2 and IGFBP-3 exist as cleaved forms in the airway tissues $[189,190]$.

TGF- $\beta 1$-mediated stimulation of ASM cell proliferation is independent of IGF-1 signaling but is associated with significant increase in phosphorylated p38 MAPK, ERK1/2, and JNK, which is inhibited by selective inhibitors of $\mathrm{p} 38$ MAPK and MAP kinase kinase (MEK) but not by IGF1 antibody [191]. Both IGFBP-3 and TGF- $\beta 1$ have been separately shown to have cell-specific growth-inhibiting or growth-potentiating effects. Addition of IGFBP-3 or TGF$\beta 1$ stimulates ASM cell growth in vitro. However, the stimulatory effects of TGF- $\beta 1$ on ASM cells seem to be mediated by IGFBP-3 in an IGF-1-independent manner. TGF- $\beta 1$ upregulates IGFBP-3, but not IGFBP-2 or IGFBP-4, peptide expression in ASM cells. TGF- $\beta 1$-stimulated ASM cell growth could be blocked by IGFBP-3 antisense oligomers as well as with an IGFBP-3 neutralizing antibody [192].

6.3. IGF-1 Signaling Activates Noncanonical Phagocytosis in Asthma. A recent study discloses novel roles of IGF-1/IGF-1R signaling in asthma [193]. The phagocytic engulfment capacity allows cells to uptake larger apoptotic cells and enhance internalization of smaller particles, which may influence inflammatory responses. Phagocytic activity of fibroblasts, airway epithelial cells, and endothelial cells are dampened in vitro by IGF-1 by phosphorylation of Akt and ERK and are further partly recovered by addition of IGF-1R inhibitors. Further in vivo experiments show that IGF-1 inhibits engulfment by airway epithelial cells but not AMs in mice, which may partly be attributed to relatively more prominent IGF$1 R$ expression in airway epithelial cells than in AMs. In addition, IGF-1 production is inducible predominantly by AMs in vivo following intranasal administration of IL-4 or IL-13. Moreover, airway epithelial-specific depletion of Igflr before, but not after, house dust mite exposure, renders mice more asthma-prone than control mice, as manifested by increased airway hyperresponsiveness, more extensive apoptosis and eosinophil, and CD4+ T cell infiltration in the lungs. These results reveal the role of IGF-1/IGF-1R in asthma by regulating phagocytosis and communication of AMs and airway epithelial cells.

In a more recent study, inflammatory responses in mice with nonorgan specific depletion of Igflr are less prominent than their controls [194]. Igflr-deficient mice exhibit no airway hyperresponsiveness, and a selective decrease in blood and BALF eosinophils, lung IL-13 levels, collagen, and smooth muscle, as well as a significant depletion of 
goblet cell metaplasia and mucus secretion markers after home dust mite exposure. The Igflr-deficient mice displayed a distinctly thinner epithelial layer than control mice. There are little data to explain the contrary responses to allergen challenge in backgrounds of nonorgan specific- or alveolar epithelial cell-specific Igflr depletion. However, sexual and systemic compensatory mechanisms may be involved, as in the latter study female mice are used and elevated Igf1 mRNA expression is documented.

6.4. IGF-1 Activates Immune Cells in Asthma. Additional data put forward the immunoregulatory role of IGF-1 in asthma, such as sensitizing immune cells including basophils, eosinophils, B lymphocytes, regulatory T cells, platelets, and stimulating the production of Th2 cytokines. IGF-1 promotes the expression of IL-13 in C5a-primed human basophils [195]. IGF-1 stimulates degranulation and histamine release of human basophils in response to IgE or FceRI-mediated stimulation [196]. Recombinant IGF-1 stimulates chemokinesis and inhibits apoptosis selectively in basophils rather than in eosinophils, neutrophils, or monocytes [197]. IGF-1 induces IgE and IgG4 production by human B lymphocytes in an IL-4- and IL-13-dependent mechanism [198]. IGF-1 increases mRNA and protein expression of the IL-4-induced type II IgE receptor (FceRII/CD23) in B cells, suggesting its immunomodulatory potential in asthma [199]. Studies revealed that $\mathrm{T}$ lymphocytes could be stimulated by Th2 cytokines such as IL-4, IL-9, IL-13, and IL-15, via IRS1/IRS-2 signaling independent of IGF-1/IGF-1R [200-202]. Recombinant human IGF-1 directly stimulates proliferation of both human and mouse regulatory $\mathrm{T}$ cells (Treg) in vitro, which has been shown to regulate allergic responses in asthma [203]. Platelets play a significant role in asthma through miR-223-induced, advanced glycation end productmediated vascular endothelial cell apoptosis via decreasing IGF-1R [204].

Positive feedback between IGF-1 and Th2 cytokines has been documented in asthma, as IGF-1 is inducible by repetitive intranasal challenge with IL-25 or IL-33 in murine asthma models [205, 206]. Another putative mediator of severe asthma, IL-17F, has been shown to induce IGF-1 expression in bronchial epithelial cells along or by costimulation with IL-4 and IL-13, suggesting an important relationship among IGF-1 signaling, Th2, and Th17 cells in asthma [207].

6.5. IGF-1 Signaling and Airway Remodeling. Airway inflammation and obstruction are induced by transition of airway epithelial cells and activation of airway fibroblasts, in which data are inconsistent regarding IGF-1. Bronchial wall remodeling is accompanied by increased number of myofibroblasts beneath the bronchial epithelial basement membrane. IGF1 increases after epithelial damage, which may enhance myofibroblast proliferation in a paracrine manner, in the coculture system of primary human bronchial myofibroblasts and a bronchial epithelial cell line [208]. Previous studies also reveal IGF-1 as a chemoattractant for migration of bronchial epithelial cells in vitro [209]. However, there are also evidences showing that TGF- $\beta 1$ induces EMT in bronchial epithelial cells via PI3K/Akt signaling independent of IGF-1
[210]. Migration of airway epithelial cells could be stimulated by IL-4, possibly via IRS-1/IRS-2 signaling independent of IGF-1/IGF-1R in an asthma model [211].

6.6. Targeting IGF-1 and IGFBP-3 in Animal Models of Asthma. Administration of an IGF-1 neutralizing antibody alleviates asthmatic outcomes including airway inflammation, subepithelial fibrosis, and elevated airway resistance in ovalbumin-challenged mice $[193,212,213]$. Expression of intercellular adhesion molecule-1 (ICAM-1) is also decreased in a dose-dependent manner without changing the levels of IL-4, IL-5, and IL-13 [213]. The expression of IGFBP-3 is high in asthmatic airway epithelial cells in situ and is increased in BALF of patients with asthma after allergen challenge. IGFBP-3 expression is upregulated by IGF-1 or TGF- $\beta 1$ in primary airway epithelial cells [214]. Administration of IGFBP-3 or IGFBP-3 gene transfer attenuates ovalbumin inhalation-induced inflammatory cell recruitment, airway hyperresponsiveness, airway thickening, serum ovalbuminspecific IgE, vascular permeability, and Th2 cytokines (IL4, IL-5, IL-13) production in mice lungs [213, 215]. IGFBP3 also reduces IGF-1 expression, and blockade of IGF-1 with an neutralizing antibody is also shown to inhibit ovalbumininduced VEGF expression, airway inflammation, and airway hyperresponsiveness [213].

Whereas IGFBP-3 seems to regulate asthmatic inflammation through inhibition of IGF-1, a non-IGF-binding IGFBP-3 mutant shows similar results. These data highlight otherwise IGF-1-independent mechanisms of IGFBP-3, which may include inactivation of ovalbumin-activated VEGF and NF$\kappa \mathrm{B}$ signaling $[213,215]$. IGFBP-3 suppresses VEGF production by both IGF-1-dependent and hypoxia-inducible factor(HIF-) dependent mechanisms, while VEGF has been shown to be associated with subepithelial fibrosis by regulation of TGF- $\beta 1$ expression through the PI3K/AKT signaling pathway in asthma $[213,216]$. IGFBP-3 inactivates NF- $\kappa \mathrm{B}$ signaling pathway in asthma in that it degrades $\mathrm{I} \kappa \mathrm{Ba}$ and $\mathrm{p} 65-\mathrm{NF}-$ $\kappa \mathrm{B}$ through IGFBP-3 receptor-mediated, IGF-1-independent activation of caspases, which further blocks TNF- $\alpha$-induced inflammation and eosinophil migration [215]. The cellular responses modified by IGF-1 signaling in asthma are depicted in Figure 3.

\section{IGF-1 Signaling in COPD}

7.1. IGF-1 Signaling in Inflammations of COPD. COPD has been redefined as a disease with both lung inflammation and systemic inflammatory responses [217]. Abnormal IGF1 signaling is present in most studies except one, which shows that circulating levels of IGF-1 are similar in patients with stable COPD as compared to control levels [218]. Other studies show that the serum levels of IGF-1 are significantly lower in COPD patients than in healthy controls, which are associated with the disease severity but not with peripheral neuropathy [219-222]. The serum levels of IGF-1 are significantly decreased in patients admitted for acute exacerbations of COPD (AECOPD) compared with those in stable stage COPD patients $[219,223,224]$ and then increase partly at the time of patients' discharge, but the serum levels of 


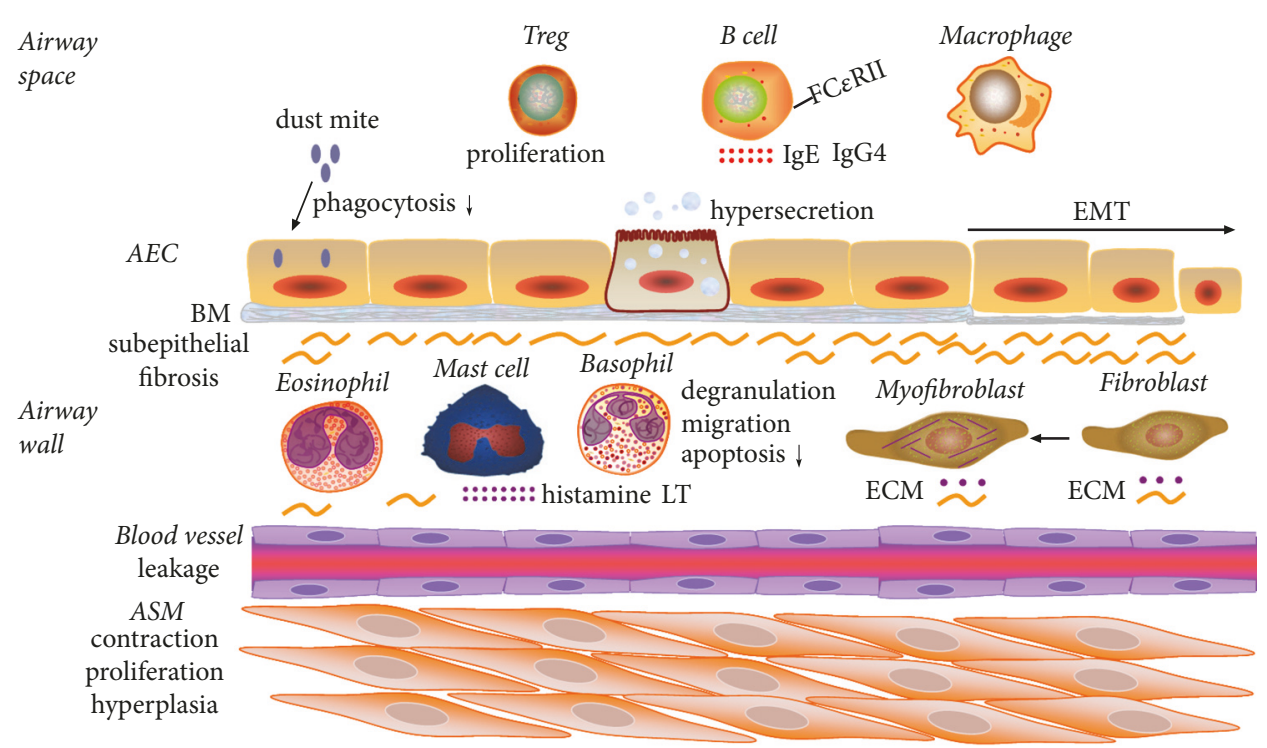

FIGURE 3: Cellular responses activated by IGF-1 in asthmatic airway inflammation. IGF-1 reduces AECs (airway epithelial cells) phagocytosis of dust mite and induces its hypersecretion, migration, and epithelial-mesenchymal transition (EMT). IGF-1 activates the proliferation of ASM (airway smooth muscle cell) and induces its contraction and hyperplasia. IGF-1 enhances blood vessel permeability. IGF-1 induces the degranulation of mast cell and basophil and release of histamine and leukotriene, activates the migration of basophils, and inhibits apoptosis. IGF-1 induces FCeRII expression and production of IgE and IgG4 in B cells. IGF-1 activates the proliferation of Treg (regulatory T cells) and activates eosinophils and macrophages. IGF-1 activates fibroblasts and myofibroblasts which generates extracellular matrix (ECM). IGF-1 activates GM-CSF, VEGF, LTD4, IL-4, IL-5, IL-13, IL-25, IL-33, IL-17A, and vice versa. BM: basal membrane.

IGF-1 both on admission and on discharge of AECOPD patients are lower than those of healthy controls [223, 224]. Emphysematous patients seem to have significantly lower IGF-1 levels compared to those with chronic bronchitis both on admission and at discharge [223].

A reasonable explanation may be that cytokines produced excessively in AECOPD disturb IGF-1 production, as 24 weeks of infliximab (a TNF- $\alpha$ antibody) treatment reduces serum levels of IGF-1 in COPD patients and TNF- $\alpha$ or IL-1 suppresses IGF-1 bioactivity via induction of IGFBP-1 synthesis both in vitro and in vivo $[225,226]$. In the study by Kythreotis et al. however, serum levels of IGF-1 are not related to levels of TNF- $\alpha$, IL-1, IL-6, and IL- 8 neither on admission nor at discharge [223]. Involvement of alternative mechanisms is thus implicated. IGF-1 signaling pathway may control the growth and fate of several lung cells in emphysema. IGF-1/IGF-1R signaling increases Bcl-2 mRNA expression and stability in airway epithelial cells in vitro via convergence of IGF-1R and EGFR signaling. Colocalization of IGF-1 and Bcl-2 is induced in airway epithelial cells by cigarette smoking in mice or is observed in lung tissues from patients with chronic bronchitis [156]. The protein and mRNA expression of IGFBP-3 are inducible in alveolar epithelial cells exposed to cigarette smoke, which could be attenuated by pretreatment of sulforaphane, an antioxidant agent. Sulforaphane decreases intracellular ROS, restores the viability of A549 cells, and attenuates G1 block of the cell cycle in cigarette smoke-exposed A549 cells [227]. Primary lung fibroblasts harvested from patients with emphysema are senescent, which express higher levels of IGFBP-3 mRNA and protein than those from controls $[228,229]$. The possible prosenescence effect of IGFBP-3 in fibroblasts is supposed to be mediated by IGFBP-3/IGF-2 interactions, not by IGF$1[230]$.

7.2. IGF-1 Signaling in Muscle Dysfunction and Metabolism of COPD. Along with overall impaired muscle strength and endurance, skeletal muscles are characterized by fibrosis and thinner muscle fibers, while necrosis, mitochondrial abnormalities, and inflammatory cell infiltration are the same in COPD patients compared to controls [231]. In some COPD cases respiratory muscles are also impacted and even cachexia develops, in which IGF-1 signaling plays an important role [232]. However, the expression trends of muscle IGF-1 mRNA or protein are inconsistent between studies. Quadriceps of IGF-1 mRNA are increased in COPD patients compared with controls [233]. IGF-1 is positively correlated with indicators of malnutrition and muscle wasting, including body weight, body mass index, thigh circumference, and albumin level [220]. The strength of quadriceps decreased in AECOPD is positively correlated with serum levels of IGF-1 [234]. Igf1 knockout reduces the thickness and the number of fibers of mice diaphragm [235]. IGF-1 mRNA levels are decreased in biopsies of vastus lateralis from hospitalized AECOPD patients [236]. Circulating IGF-1 levels are similar in cachectic versus noncachectic COPD patients [237]. However, muscle IGF-1 protein is decreased more in cachectic COPD patients compared with noncachectic patients [238]. Testosterone and/or resistance training strengthens quadriceps muscle synthesis in COPD patients by increasing local IGF-1 expression [239].

Pulmonary rehabilitation induces mRNA and protein expressions of IGF-1 in vastus lateralis, which are associated 
with improvement of muscle quality and strength in COPD patients [240]. IGF-1 protein levels in quadriceps increase more in noncachectic patients than in cachectic COPD patients after pulmonary rehabilitation training [238]. Improved six-minute walk test performance is associated with increased levels of serum IGF-1 and IGFBP-3 following pulmonary rehabilitation in COPD patients [241]. The roles of IGF-1 in muscle metabolism are further proved in animal models of chronic cigarette smoke exposure. Compared to controls, rodents chronically exposed to cigarette smoke are presented with significantly lower plasma IGF-1 levels and decreased IGF-1 mRNA and protein expression in the gastrocnemius, which may be associated with reduced body weight and food intake, systemic inflammation, skeletal muscle wasting, and reduced skeletal muscle strength [242, 243]. Exogenous rhIGF-I attenuates diaphragm fiber atrophy induced by triamcinolone administration in a hamster model of pancreatic elastase-induced emphysema and prevents them from significant weight loss without interfering blood glucose levels [244]. Administration of rhIGF-1 completely prevented atrophy and growth arrest of all diaphragm fibers in rats with moderate caloric deficit [245]. In animal studies of chronic hypoxia exposure, recombinant human IGF-1 significantly ameliorates protein catabolism and promotes anabolism, increases serum total protein and albumin, and earns greater weight gain than vehicle [246, 247]. Notably, hypoxia and caloric deficit are common in COPD patients which may exacerbate muscle dysfunction [248].

7.3. IGF-1 Signaling and Aging in COPD. IGF-1 signaling pathway has been proposed as a target for aging-related diseases $[249,250]$. As accelerated lung aging features COPD, conquering aging becomes a promising therapeutic route for COPD [251]. Direct evidences for IGF-1 signaling in aging are also shown. IGF-1 knockdown protects mice from paraquat-induced oxidative stress and death and prolongs mice lifespan by inhibiting MAPK/ERK1/2 and Akt signaling [252]. IGF-1 protects from DNA injury and facilitates repair [253]. Excessive IGF-1 inhibits autophagy via Akt/mTOR signaling in cigarette smoke extract-treated human bronchial epithelial cells, which further modulates cell senescence and contributes to the pathogenesis of COPD [254]. IGFBP-3 may also regulate senescence of alveolar epithelial cells and lung fibroblasts in emphysema [223-225]. These data offer IGF1 signaling pathway as a potential target for aging in COPD $[255,256]$.

\section{IGF-1 Signaling in Cystic Fibrosis (CF)}

CF is caused by mutations in the gene that encodes cystic fibrosis transmembrane conductance regulator (CFTR) protein [270]. CFTR protein is an epithelial chloride channel that regulates transepithelial transport of sodium and bicarbonate. This leads to a collection of systemic manifestations, which involves the pulmonary, digestive, reproductive, and endocrine system [270-272]. Ninety percent of CF patients die for progressive lung disease, and airway inflammation is an important feature for CF [270, 273]. Both lung inflammation and systemic responses in CF patients are associated with inhibited IGF-1 signaling. CF patients have significantly lower serum and BALF levels of IGF-1 compared with health controls [257-261] and higher serum levels of IGFBP-2 [260]. Low serum levels of IGF-1 and high levels of serum IGFBP-2 are associated with increased IL$1 \beta$, IL- 6 , and TNF- $\alpha$ levels [260]. The number of IGF- 1 and $\mathrm{Bcl}-2$ double-positive AECs is elevated in lung specimens from CF patients, which suggests an antiapoptotic effect of IGF-1, possibly mediated by PI3K/Akt signaling [156]. IGF-1 expression is accompanied by increased numbers of myofibroblasts, collagen I deposition, alveolar inflammation, and elastin degradation in CF lung tissues [258]. Serum IGF-1 levels fall significantly in pulmonary exacerbation of CF from baseline, which might be improved further by intravenous antibiotic treatment [257]. IGF-1-positive staining in AECs and macrophages are distributed in lung tissue specimens from CF patients with Pseudomonas aeruginosa colonization prior to lung transplantation [258]. AMs isolated from BALF of CF patients exhibit impaired phagocytosis activity in culture with Pseudomonas aeruginosa, which could be dosedependently improved by exogenous IGF-1 [259].

Notably, pigs, mice, or humans with CF are born with reduced serum insulin-like growth factor 1 (IGF-1) levels $[262,263]$. There are several potential mechanisms underlying downregulation of IGF-1 signaling in CF. CFTR deficiency activates sulfotransferase 1E1 (SULT1E1), which inhibits IGF1 synthesis by inactivation of beta-estradiol at physiological concentrations via conjugation with sulfonate $[274,275]$. On the other hand, IGF-1 enhances stable CFTR expression and CFTR-mediated chloride transport in CF cell lines, which depends on activation of TC10 and inactivation of CFTRassociated ligand (CAL) [276]. IGF-1-activated TC10 changes the interaction of CFTR and CAL in the Golgi, allowing CFTR to progress to the plasma membrane instead of trafficking to the cell surface for degradation [276, 277]. Taking these data together, CFTR deficiency and decreased IGF1 signaling constitute the positive feedback that exacerbate each other. Furthermore, IGF-1 may be regulated by IGFBPs, $\mathrm{GH}$, and insulin metabolism. Serum IGFBP-3 levels might be decreased [278], while IGFBP-2 levels may increase in CF patients [259]. Normal spontaneous and stimulated GH levels but low levels of IGF-1 and IGFBP-3 suggest a state of relative GH insensitivity in children with CF $[279,280]$. There is also a significant association between plasma insulin area under curve and serum IGFBP-3, and patients whose insulin secretion is most impaired had lower serum IGFBP-3 levels but higher IGFBP-1 levels than normal controls [276]. Thus insulin deficiency may disturb the GH/IGF-1 axis as a result of reduced levels of IGFBP-3 and increased levels of inhibitory IGFBP-1 [281, 282].

Reduced IGF-1 signaling has endocrine and metabolic implications in CF. Progressive insulin deficiency may reduce IGF-1 levels and IGF-1 bioactivity and disturb weight gain and statural growth in CF [281]. Serum IGF-1 levels are directly correlated with FEV1\%, serum iron, hemoglobin concentration, and transferrin saturation [257-259, 264]. Both IGF-1 and IGFBP-3 levels are correlated with height, weight, BMI, and protein catabolism, which reflect growth retardation in prepubertal CF patients $[265,266,278-280]$. In an animal 
model of CF, serum Igfbp-3 levels are increased, while Igf-1, albumin, and triglycerides measures are decreased compared with wild-type mice [280]. Recombinant human IGFBP-3 treatment significantly increased serum albumin and triglycerides but did not affect weight gain in CF mice [283]. Except for intertwining with GH and insulin, IGF-1 may also regulate metabolism by upregulating the depressed expression of FOXO1 in CF [284].

Since IGF-1 and GH are downregulated and associated with inflammation, metabolism, and development in CF patients, supplement of exogenous IGF-1 or GH seems to be a rational therapy. Administration of recombinant growth hormone significantly increases height, growth velocity, and serum levels of IGF-1 and IGFBP-3, but not lung functions [285]. Meta-analyses show that growth hormone therapy improves the intermediate outcomes in height, weight, and lean tissue mass, but pulmonary function improvement is inconsistent [286]. No significant changes in quality of life, clinical status, or side-effects are observed [287]. Both commercialized rhIGF-1 (mecasermin) and recombinant human IGFBP-3 have been available and approved by the U.S. Food and Drug Administration (FDA) for over 10 years [288, 289]. In a clinical trial, treatment with IGF-1 significantly increases serum IGF-1 levels in prepubertal children with CF but does not result in significant difference in linear growth rate, weight gain, rate of accretion of lean body mass, or mean FEV1 as compared with placebo [267]. It is argued that higher dose of IGF-1 treatment may bring about higher efficacy in CF, but insulin sensitivity might be impaired as well [288]. In a case report, prolonged use of rhIGF-1 significantly improves body growth, stabilizes lung function, and reduces the need of insulin for glycemic control in a child with CF [267]. This indicates the long-term safety and efficacy of rhIGF-1 for patients with CF-associated growth failure. However, data are insufficient with regard to lung and systemic inflammations before and after long-term rhIGF-1 administration. A prospective study was terminated for insufficient recruitment, which aims to investigate the efficacy of rhIGF-1 on body weight and composition within 28 weeks in CF adults [268]. rhIGF-1 treatment is thus promising for restoring GH/IGF-1 axis, metabolism, and growth in CF patients, but its efficacy in lung inflammation and immunology awaits further investigations.

There are concerns that IGF-1 might have roles in nonCF bronchiectasis like in CF. However, there are currently no direct evidences for or against this. According to Jian et al., 46\% RA-ILD patients have bronchiectasis on HRCT scan, and serum levels of IGF-1 are increased in RA-ILD compared to those in RA and control subjects [89]. The prevalence of mild cylindrical bronchiectasis is $22.2 \%$ in 36 patients with acromegaly but is not statistically different from 24 control subjects $(16.7 \%)$ and is not associated with serum levels of IGF-1 ( $P=0.74)$ [41]. Another study by Camilo et al. shows $35 \%$ of 20 patients with acromegaly have bronchiectasis, but serum IGF-1 levels are not statistically associated with lung function changes [290]. Taken these data together, rheumatoid arthritis- or acromegaly-assicated bronchiectasis is not associated with changes of serum IGF-1 levels. Despite the similarities of $\mathrm{CF}$ and non-CF bronchiectasis, there are currently no evidences supporting the supplemental administration of rhIGF-1 in stable bronchiectasis or acute exacerbations of bronchiectasis [291].

\section{Conclusions and Future Directions}

In this article, we reviewed the up-to-date roles and possible mechanisms of IGF-1 signaling pathway in lung development and inflammatory diseases including BPD, pulmonary fibrosis, ALI and ARDS, asthma, COPD, and CF. As abnormal IGF-1 signaling disrupts alveolar development, it is even more important to know how IGF-1 signaling manipulates different cells in the precise time and space sequence and its crosstalk with other signaling pathways, both in normal and in abnormal circumstances. Whereas components of IGF1 signaling pathways are potentiated as biomarkers as they are dysregulated locally or systemically in inflammatory lung diseases, data may be inconsistent or even be paradoxical among different studies (summarized in Table 1). This could be partly attributed to the complexity of IGF-1, which serves both as an important part of the growth hormone/IGF-1 axis and also as a regulator of systemic metabolism. And the molecular-, time-, and organ-dependent and individualized IGF-1 signaling further obscures the potentials of its components for being candidate biomarkers for lung diseases [154]. Moreover, IGF-1/IGF-1R antibodies are well tolerated in clinical trials but fail to generate overall therapeutic advantages in patients with small cell lung cancer or in patients with non-small cell lung cancer by combination with chemotherapy or tyrosine kinase inhibitors (TKIs) [12$16,269]$. These unfavorable outcomes include retraction of earlier publications of a phase II trial data, following a thorough investigation of the previously reported survival results [292]. The usage of IGF-1-based agents urges for more researches in developmental disorders and inflammatory lung diseases, as current data are generally collected from limited number of animal experiments and are less exuberant than those in lung cancer. An exception is the successful usage of rhIGF-1 in a few CF cases, although rhIGF-1 seems to improve metabolism and development most. IGF-1 antibody, rhIGF-1, and rhIGFBP-3 are commercially available and under investigations for clinical efficacy in patients with lung diseases, as described in Table 2. Much is still awaiting elucidations regarding this issue that direct us towards further research directions. By integrating bench-bed research methods, rational clinical diagnostic and therapeutic approaches concerning IGF-1 signaling might become applicable in lung disorders in the next few years.

\section{Abbreviations}

$\alpha$-SMA: Alpha-smooth muscle actin

rhIGF-1: Recombinant human insulin-like growth factor-1

AEC: $\quad$ Alveolar epithelial cell

AECOPD: Acute exacerbation of chronic obstructive pulmonary disease

ALI: $\quad$ Acute lung injury

AM: Alveolar macrophage 


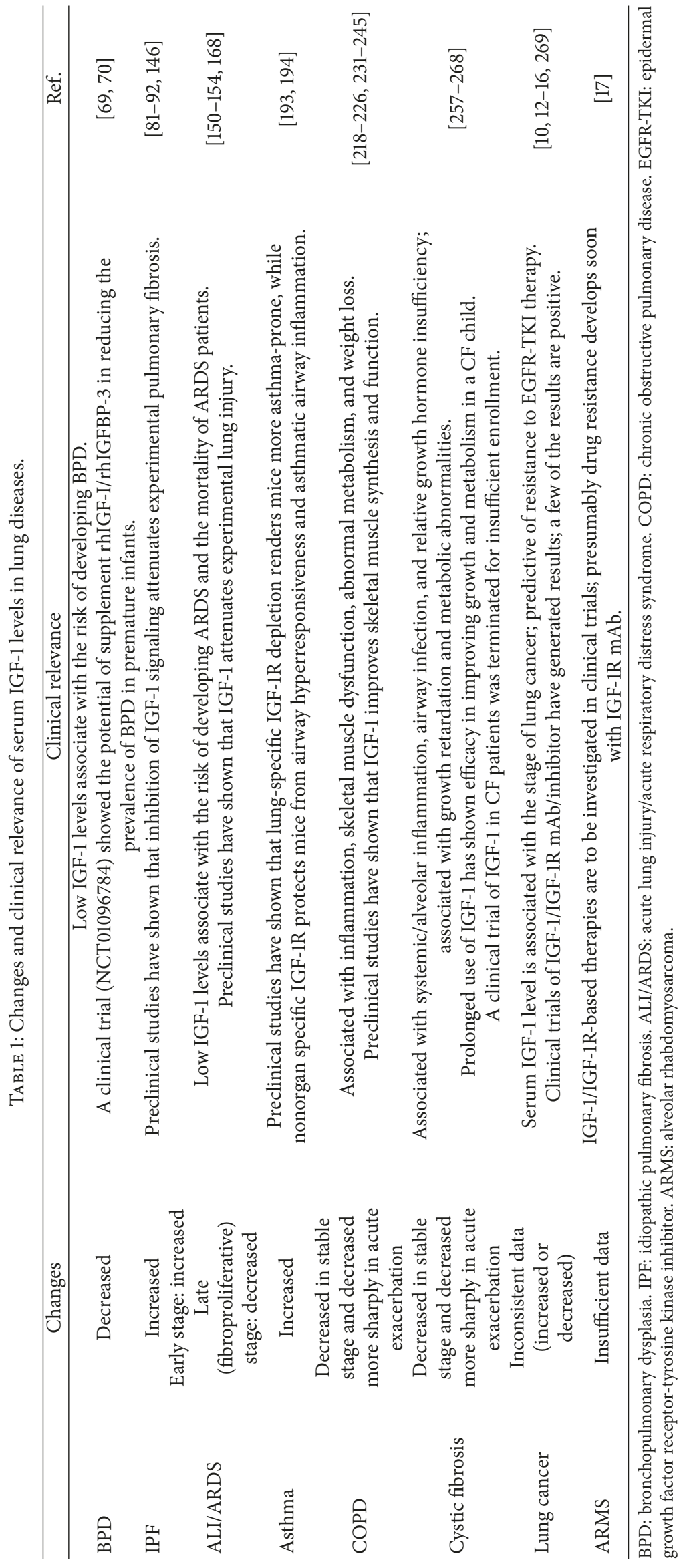




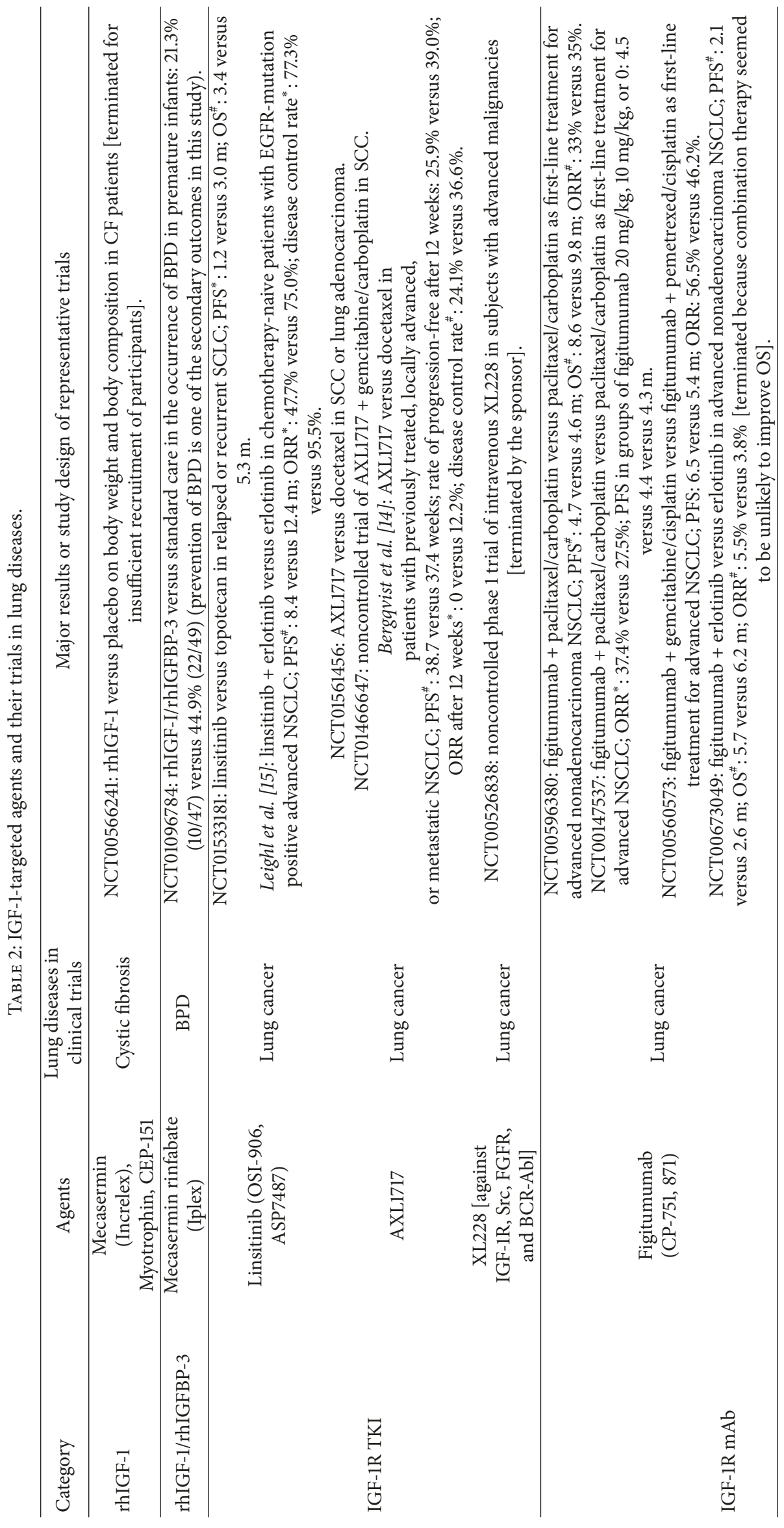




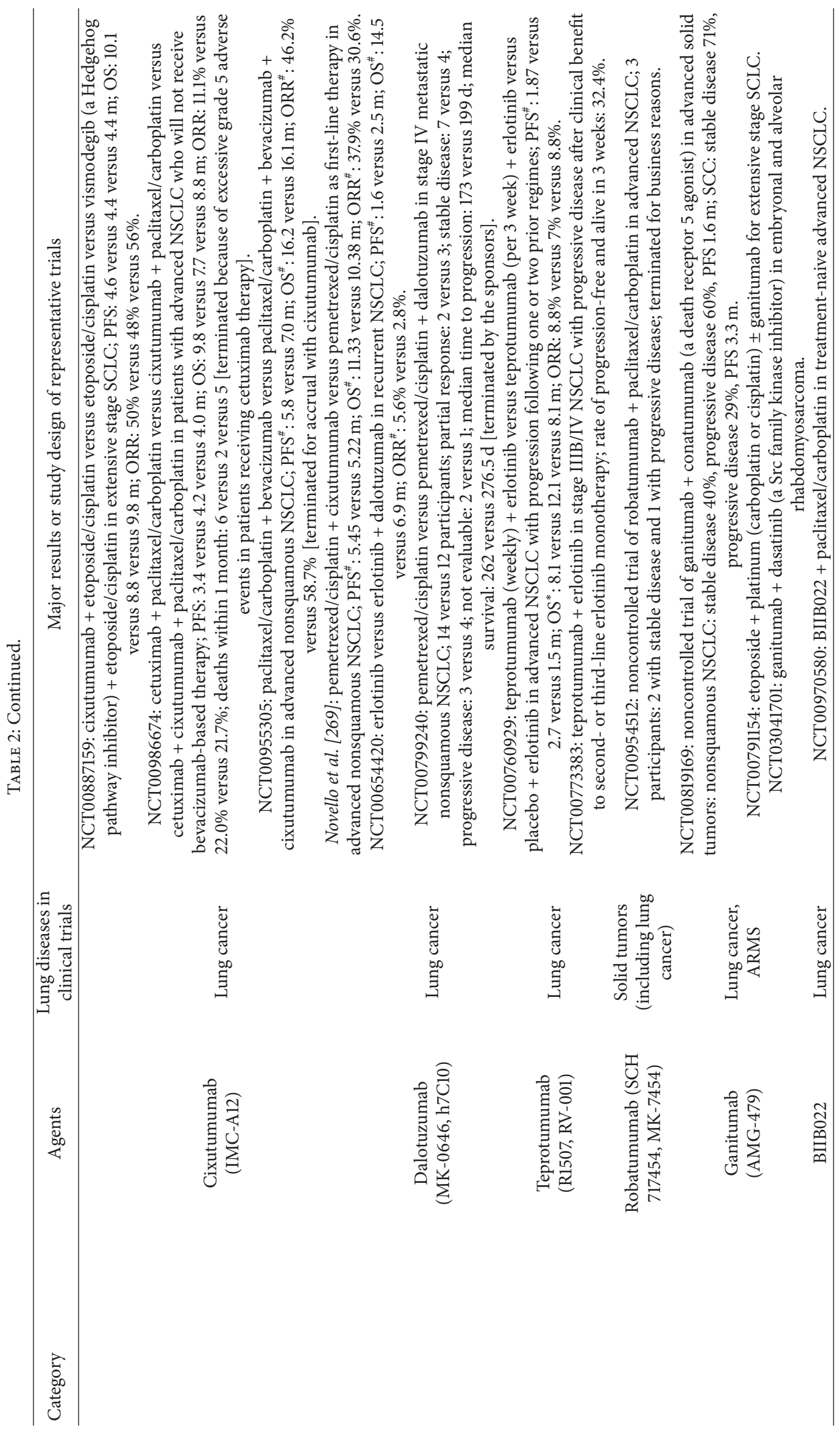




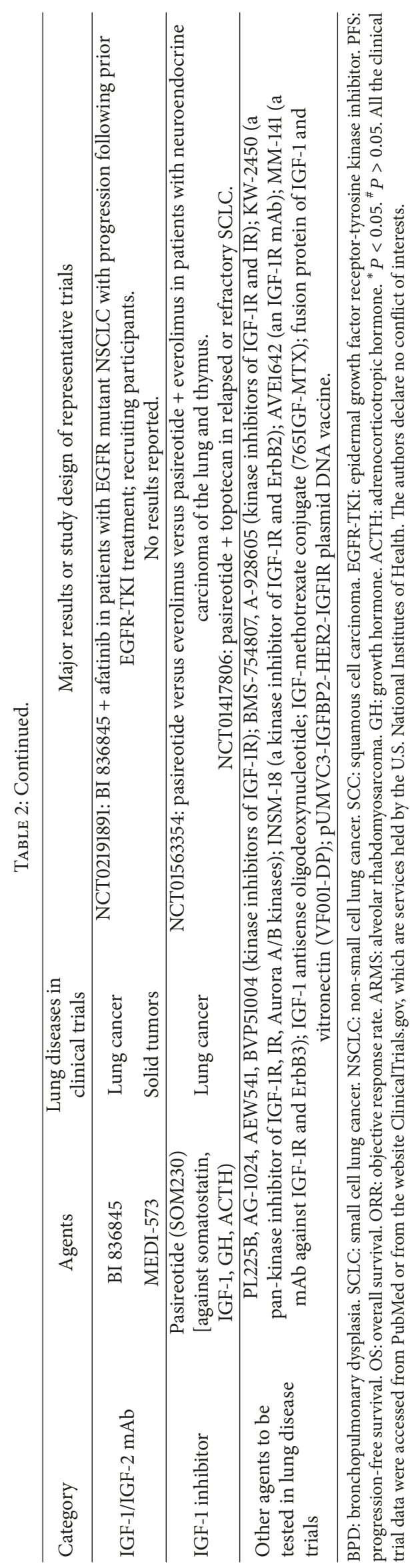


ARDS: Acute respiratory distress syndrome

ASM: $\quad$ Airway smooth muscle

ATI: $\quad$ Type I alveolar epithelial cell

ATII: $\quad$ Type II alveolar epithelial cell

BALF: Bronchoalveolar lavage fluid

BPD: Bronchopulmonary dysplasia

CCSP: Clara cell secretory protein

CF: $\quad$ Cystic fibrosis

CFTR: Cystic fibrosis transmembrane conductance regulator

COPD: Chronic obstructive pulmonary disease

CTGF: Connective tissue growth factor

ECM: $\quad$ Extracellular matrix

EGFR: Epidermal growth factor receptor

EMT: Epithelial-mesenchymal transition

$\mathrm{ENaC}$ : Epithelial sodium channel

ERK: $\quad$ Extracellular signal-regulated kinase

FGF: Fibroblast growth factor

GH: $\quad$ Growth hormone

GM-CSF: Granulocyte macrophage colony stimulating factor

IFN- $\gamma$ : Interferon- $\gamma$

IGF-1: Insulin-like growth factor-1

IGF-1R: IGF-1 receptor

IGF-2: Insulin-like growth factor-2

IGF-2R: IGF-2 receptor

IGFBP: IGF binding protein

IGFBP-rP: IGF binding protein-related protein

IPF: Idiopathic pulmonary fibrosis

IR: Insulin receptor

IRS: Insulin receptor substrates

JNK: C-Jun N-terminal kinase

LPS: Lipopolysaccharide

LTB4: Leukotriene B4

MAPK: Mitogen-activated protein kinase

MTOR: Mammalian target of rapamycin

NEDD4: Neural precursor cell-expressed developmentally downregulated protein 4

NF- $\kappa$ B: $\quad$ Nuclear factor- $\kappa$ B

PDGF: Platelet-derived growth factor

PI3K: $\quad$ Phosphoinositide-3-kinase

RTK: $\quad$ Receptor tyrosine kinase

SGK-1: $\quad$ Serum- and glucocorticoid-dependent kinase

SPC: $\quad$ Surfactant protein C

TGF- $\beta$ : $\quad$ Transforming growth factor- $\beta$

TNF- $\alpha$ : $\quad$ Tumor necrosis factor- $\alpha$

VEGF: Vascular endothelial growth factor

Wnt: Wingless/intl.

\section{Conflicts of Interest}

The authors declare no conflicts of interest.

\section{Authors' Contributions}

Zheng Wang and Wenting Li contributed equally to this work.

\section{Acknowledgments}

This work was partly supported by the National Natural Science Foundation of China (Grant no. 81600047 to Zheng Wang; Grants no. 81472835 and no. 81670091 to Xiaoju Zhang), the Natural Science Foundation of Henan Province (Grants no. 142300410381 and no. 142102310409 to Zheng Wang), the Youth Key Research Program of Henan Province (Grant no. 154100510021 to Xiaoju Zhang), the Natural Science Foundation of Anhui Province (Grant no. 1508085MH172 to Wenting Li), International Cooperative Project of Anhui Province (Grant no. 1704e1002231 to Wenting Li), WBE Liver Fibrosis Foundation (Grant no. CFHPC20161005 to Wenting Li), Tianqing Liver Diseases Research Fund (Grant no. TQGB20140075 to Wenting Li), and Zhengzhou Program on Research for Public Good (Grant no. 163PKJHM196 to Yuming Wang).

\section{References}

[1] S. Yakar and M. L. Adamo, "Insulin-Like Growth Factor 1 Physiology. Lessons from Mouse Models.," Endocrinology and Metabolism Clinics of North America, vol. 41, no. 2, pp. 231-247, 2012.

[2] F. Nurwidya, S. Andarini, F. Takahashi, E. Syahruddin, and K. Takahashi, "Implications of insulin-like growth factor 1 receptor activation in lung cancer," Malaysian Journal of Medical Sciences, vol. 23, no. 3, pp. 9-21, 2016.

[3] A. Trueba-Saiz, A. M. Fernandez, T. Nishijima et al., "Circulating insulin-like growth factor i regulates its receptor in the brain of male mice," Endocrinology, vol. 158, no. 2, pp. 349-355, 2017.

[4] J. T. Allen, C. A. Bloor, R. K. Kedia, R. A. Knight, and M. A. Spiteri, "Expression of growth hormone-releasing factor, growth hormone, insulin-like growth factor-1 and its, binding proteins in human lung," Neuropeptides, vol. 34, no. 2, pp. 98107, 2000.

[5] A. D. Stiles and A. J. D'Ercole, “The insulin-like growth factors and the lung.," American Journal of Respiratory Cell and Molecular Biology, vol. 3, no. 2, pp. 93-100, 1990.

[6] W.-Y. Kim, Q. Jin, S.-H. Oh et al., "Elevated epithelial insulinlike growth factor expression is a risk factor for lung cancer development," Cancer Research, vol. 69, no. 18, pp. 7439-7448, 2009.

[7] M. J. Fidler, D. D. Shersher, J. A. Borgia, and P. Bonomi, "Targeting the insulin-like growth factor receptor pathway in lung cancer: Problems and pitfalls," Therapeutic Advances in Medical Oncology, vol. 4, no. 2, pp. 51-60, 2012.

[8] G. V. Scagliotti and S. Novello, "The role of the insulin-like growth factor signaling pathway in non-small cell lung cancer and other solid tumors," Cancer Treatment Reviews, vol. 38, no. 4, pp. 292-302, 2012.

[9] H. Cao, G. Wang, L. Meng et al., "Association between Circulating Levels of IGF-1 and IGFBP-3 and Lung Cancer Risk: A MetaAnalysis," PLoS ONE, vol. 7, no. 11, Article ID e49884, 2012.

[10] X. Qu, Z. Wu, W. Dong et al., "Update of IGF-1 receptor inhibitor (ganitumab, dalotuzumab, cixutumumab, teprotumumab and figitumumab) effects on cancer therapy," Oncotarget , vol. 8, no. 17, pp. 29501-29518, 2017. 
[11] A. Kasprzak, W. Kwasniewski, A. Adamek, and A. GozdzickaJozefiak, "Insulin-like growth factor (IGF) axis in cancerogenesis," Mutation Research - Reviews in Mutation Research, vol. 772, pp. 78-104, 2017.

[12] A. A. Chiappori, G. A. Otterson, A. Dowlati et al., "A randomized phase II study of linsitinib (OSI-906) versus Topotecan in patients with relapsed small-cell lung cancer," The Oncologist, vol. 21, no. 10, pp. 1163-1164, 2016.

[13] C. J. Langer, A. J. Olszanski, D. D. Karp et al., "Randomized, phase III trial of first-line figitumumab in combination with paclitaxel and carboplatin versus paclitaxel and carboplatin alone in patients with advanced non-small-cell lung cancer," Journal of Clinical Oncology, vol. 32, no. 19, pp. 2059-2066, 2014.

[14] M. Bergqvist, G. Holgersson, I. Bondarenko et al., "Phase II randomized study of the IGF-1R pathway modulator AXL1717 compared to docetaxel in patients with previously treated, locally advanced or metastatic non-small cell lung cancer," Acta Oncologica, vol. 56, no. 3, pp. 441-447, 2017.

[15] N. B. Leighl, N. A. Rizvi, L. G. de Lima et al., "Phase 2 Study of Erlotinib in Combination With Linsitinib (OSI-906) or Placebo in Chemotherapy-Naive Patients With Non-SmallCell Lung Cancer and Activating Epidermal Growth Factor Receptor Mutations," Clinical Lung Cancer, vol. 18, no. 1, pp. 3442, 2017.

[16] C. H. Huang, S. K. Williamson, P. Neupane et al., "Impact study: MK-0646 (Dalotuzumab), insulin growth factor 1 receptor antibody combined with pemetrexed and cisplatin in stage IV metastatic non-squamous lung cancer," Frontiers in Oncology, vol. 5, article no. 301, 2016.

[17] J. C. Van Gaal, M. H. S. Roeffen, U. E. Flucke et al., "Simultaneous targeting of insulin-like growth factor-1 receptor and anaplastic lymphoma kinase in embryonal and alveolar rhabdomyosarcoma: A rational choice," European Journal of Cancer, vol. 49, no. 16, pp. 3462-3470, 2013.

[18] M. Sun, R. Ramchandran, J. Chen, Q. Yang, and J. U. Raj, "Smooth muscle Insulin-like growth factor-1 mediates hypoxiainduced pulmonary hypertension in neonatal mice," American Journal of Respiratory Cell and Molecular Biology, vol. 55, no. 6, pp. 779-791, 2016.

[19] R. J. McAnulty, D. Guerreiro, A. D. Cambrey, and G. J. Laurent, "Growth factor activity in the lung during compensatory growth after pneumonectomy: Evidence of a role for IGF-1," European Respiratory Journal, vol. 5, no. 6, pp. 739-747, 1992.

[20] J. I. Jones and D. R. Clemmons, "Insulin-like growth factors and their binding proteins: biological actions," Endocrine Reviews, vol. 16, no. 1, pp. 3-34, 1995.

[21] W. D. Salmon Jr. and W. H. Daughaday, "A hormonally controlled serum factor which stimulates sulfate incorporation by cartilage in vitro," The Journal of Laboratory and Clinical Medicine, vol. 49, no. 6, pp. 825-836, 1957.

[22] G. Goldspink and S. Y. Yang, "The Splicing of the IGF-I Gene to Yield Different Muscle Growth Factors," Advances in Genetics, vol. 52, pp. 23-49, 2004.

[23] A. Belfiore, F. Frasca, G. Pandini, L. Sciacca, and R. Vigneri, "Insulin receptor isoforms and insulin receptor/insulin-like growth factor receptor hybrids in physiology and disease," Endocrine Reviews, vol. 30, no. 6, pp. 586-623, 2009.

[24] A. J. Casa, R. K. Dearth, B. C. Litzenburger, A. V. Lee, and X. Cui, "The type I insulin-like growth factor receptor pathway: A key player in cancer therapeutic resistance," Frontiers in Bioscience, vol. 13, no. 9, pp. 3273-3287, 2008.
[25] V. Hwa, Y. Oh, and R. G. Rosenfeld, "The insulin-like growth factor-binding protein (IGFBP) superfamily," Endocrine Reviews, vol. 20, no. 6, pp. 761-787, 1999.

[26] A. Juul, "Serum levels of insulin-like growth factor I and its binding proteins in health and disease," Growth Hormone \& IGF Research, vol. 13, no. 4, pp. 113-170, 2003.

[27] R. Liang, A. Khanna, S. Muthusamy et al., "Post-transcriptional regulation of IGF1R by key microRNAs in long-lived mutant mice," Aging Cell, vol. 10, no. 6, pp. 1080-1088, 2011.

[28] L. Pirola, O. Zerzaihi, H. Vidal, and F. Solari, "Protein acetylation mechanisms in the regulation of insulin and insulin-like growth factor 1 signalling," Molecular and Cellular Endocrinology, vol. 362, no. 1-2, pp. 1-10, 2012.

[29] A. C. Panda, I. Grammatikakis, J.-H. Yoon, and K. Abdelmohsen, "Posttranscriptional regulation of insulin family ligands and receptors," International Journal of Molecular Sciences, vol. 14, no. 9, pp. 19202-19229, 2013.

[30] H. J. Jung and Y. Suh, "Regulation of IGF-1 signaling by microRNAs," Front Genet, vol. 5, p. 472, 2015.

[31] T.-C. Liu, M.-J. Hsieh, M.-C. Liu, W.-L. Chiang, T. C.-Y. Tsao, and S.-F. Yang, "The clinical significance of the insulinlike growth factor-1 receptor polymorphism in non-small-cell lung cancer with epidermal growth factor receptor mutation," International Journal of Molecular Sciences, vol. 17, no. 5, article no. 763, 2016.

[32] J. Beattie, L. McIntosh, and C. F. Van Der Walle, "Crosstalk between the insulin-like growth factor (IGF) axis and membrane integrins to regulate cell physiology," Journal of Cellular Physiology, vol. 224, no. 3, pp. 605-611, 2010.

[33] M. Maghnie, S. Loche, M. Cappa, L. Ghizzoni, and R. Lorini, "Hormone resistance and hypersensitivity: From genetics to clinical management," Endocrine Development, vol. 24, pp. 128137, 2013.

[34] M. J. E. Walenkamp, M. Losekoot, and J. M. Wit, "Molecular IGF-1 and IGF-1 receptor defects: From genetics to clinical management," Endocrine Development, vol. 24, pp. 128-137, 2013.

[35] E. W. Roback, A. J. Barakat, V. G. Dev, M. Mbikay, M. Chretien, and M. G. Butler, "An infant with deletion of the distal long arm of chromosome 15 (q26.1 $\rightarrow$ qter) and loss of insulin-like growth factor 1 receptor gene," American Journal of Medical Genetics, vol. 38, no. 1, pp. 74-79, 1991.

[36] K. A. Woods, C. Camacho-Hübner, M. O. Savage, and A. J. L. Clark, "Intrauterine growth retardation and postnatal growth failure associated with deletion of the insulin-like growth factor I gene," The New England Journal of Medicine, vol. 335, no. 18, pp. 1363-1367, 1996.

[37] A. Denley, C. C. Wang, K. A. McNeil et al., "Structural and functional characteristics of the Val44Met insulin-like growth factor I missense mutation: Correlation with effects on growth and development," Molecular Endocrinology, vol. 19, no. 3, pp. 711-721, 2005.

[38] I. Netchine, S. Azzi, Y. Le Bouc, and M. O. Savage, "IGF1 molecular anomalies demonstrate its critical role in fetal, postnatal growth and brain development," Best Practice \& Research Clinical Endocrinology \& Metabolism, vol. 25, no. 1, pp. 181-190, 2011.

[39] A. Grimberg, S. A. DiVall, C. Polychronakos et al., "Guidelines for Growth Hormone and Insulin-Like Growth FactorI Treatment in Children and Adolescents: Growth Hormone Deficiency, Idiopathic Short Stature, and Primary Insulin-Like 
Growth Factor-I Deficiency," Hormone Research in Paediatrics, vol. 86, no. 6, pp. 361-397, 2017.

[40] I. Ben-Dov, M. Gaides, M. Scheinowitz, R. Wagner, and Z. Laron, "Reduced exercise capacity in untreated adults with primary growth hormone resistance (Laron syndrome)," Clinical Endocrinology, vol. 59, no. 6, pp. 763-767, 2003.

[41] M. P. Rodrigues, L. A. Naves, C. A. Viegas et al., "Prevalence of lung structure abnormalities in patients with acromegaly and their relationship with gas exchange: Cross-sectional analytical study with a control group," São Paulo Medical Journal, vol. 133, no. 5, pp. 394-400, 2015.

[42] A. Benfante, A. Ciresi, M. Bellia et al., "Early Lung Function Abnormalities in Acromegaly," Lung, vol. 193, no. 3, pp. 393-399, 2015.

[43] C. Mesas-Burgos, M. Nord, L. Didon, A.-C. Eklöf, and B. Frenckner, "Gene expression analysis after prenatal tracheal ligation in fetal rat as a model of stimulated lung growth," Journal of Pediatric Surgery, vol. 44, no. 4, pp. 720-728, 2009.

[44] P. J. Pringle, M. P. P. Geary, C. H. Rodeck, J. C. P. Kingdom, S. Kayamba-Kay'S, and P. C. Hindmarsh, "The influence of cigarette smoking on antenatal growth, birth size, and the insulin-like growth factor axis," The Journal of Clinical Endocrinology \& Metabolism, vol. 90, no. 5, pp. 2556-2562, 2005.

[45] V. L. Clifton, N. A. Hodyl, V. E. Murphy, W. B. Giles, R. C. Baxter, and R. Smith, "Effect of maternal asthma, inhaled glucocorticoids and cigarette use during pregnancy on the newborn insulin-like growth factor axis," Growth Hormone \& IGF Research, vol. 20, no. 1, pp. 39-48, 2010.

[46] K. F. Meyer, S. Krauss-Etschmann, W. Kooistra et al., "Prenatal exposure to tobacco smoke sex dependently influences methylation and mRNA levels of the Igf axis in lungs of mouse offspring," American Journal of Physiology-Lung Cellular and Molecular Physiology, vol. 312, no. 4, pp. L542-L555, 2017.

[47] S. Radom-Aizik, F. P. Zaldivar, D. M. Nance, F. Haddad, D. M. Cooper, and G. R. Adams, "Growth inhibition and compensation in response to neonatal hypoxia in rats," Pediatric Research, vol. 74, no. 2, pp. 111-120, 2013.

[48] C. J. Green, J. M. Holly, C. E. Bolton, A. Bayer, S. Ebrahim, and J. Gallacher, "Role of IGF-I, IGF-II and IGFBP-3 in lung function of males: the Caerphilly Prospective Study," International Journal of Molecular Epidemiology and Genetics, vol. 5, pp. 112-119, 2014.

[49] S. Gläser, N. Friedrich, R. Ewert et al., "Association between serum insulin-like growth factor (IGF) I and IGF binding protein-3 and lung function," The Journal of Clinical Endocrinology \& Metabolism, vol. 94, no. 7, pp. 2452-2458, 2009.

[50] K. Piotrowska, S. J. Borkowska, B. Wiszniewska et al., "The effect of low and high plasma levels of insulin-like growth factor-1 (IGF-1) on the morphology of major organs: Studies of laron dwarf and bovine growth hormone transgenic (bGHTg) mice," Histology and Histopathology, vol. 28, no. 10, pp. 1325-1336, 2013.

[51] J. A. Beyea, D. M. Olson, and S. Harvey, "Growth hormonedependent changes in the rat lung proteome during alveorization," Molecular and Cellular Biochemistry, vol. 321, no. 1-2, pp. 197-204, 2009.

[52] C. J. Quaife, L. S. Mathews, C. A. Pinkert, R. E. Hammer, R. L. Brinster, and R. D. Palmiter, "Histopathology associated with elevated levels of growth hormone and insulin-like growth factor I in transgenic mice," Endocrinology, vol. 124, no. 1, pp. 40-48, 1989.
[53] J.-P. Liu, J. Baker, A. S. Perkins, E. J. Robertson, and A. Efstratiadis, "Mice carrying null mutations of the genes encoding insulin-like growth factor I (Igf-1) and type 1 IGF receptor (Igf1r)," Cell, vol. 75, no. 1, pp. 59-72, 1993.

[54] R. Epaud, F. Aubey, J. Xu et al., "Knockout of Insulin-Like Growth Factor-1 Receptor Impairs Distal Lung Morphogenesis," PLoS ONE, vol. 7, no. 11, p. e48071, 2012.

[55] I. P. López, L. Rodriguez-de la Rosa, R. S. Pais et al., "Differential organ phenotypes after postnatal Igf1r gene conditional deletion induced by tamoxifen in UBC-CreERT2; Igflr fl/fl double transgenic mice," Transgenic Research, vol. 24, no. 2, pp. 279294, 2015.

[56] Y. Wu, H. Sun, S. Yakar, and D. LeRoith, "Elevated levels of insulin-like growth factor (IGF)-I in serum rescue the severe growth retardation of IGF-I null mice," Endocrinology, vol. 150, no. 9, pp. 4395-4403, 2009.

[57] R. S. Pais, N. Moreno-Barriuso, I. Hernández-Porras, I. P. López, J. De Las Rivas, and J. G. Pichel, "Transcriptome analysis in prenatal IGF1-deficient mice identifies molecular pathways and target genes involved in distal lung differentiation," PLoS ONE, vol. 8, no. 12, Article ID e83028, 2013.

[58] C. Günschmann, H. Stachelscheid, M. Akyüz et al., "Insulin/ IGF-1 Controls Epidermal Morphogenesis via Regulation of FoxO-Mediated p63 Inhibition," Developmental Cell, vol. 26, no. 2, pp. 176-187, 2013.

[59] L. A. Galvis, A. Z. Holik, K. M. Short et al., "Repression of Igf1 expression by Ezh2 prevents basal cell differentiation in the developing lung," Development, vol. 142, no. 8, pp. 1458-1469, 2015.

[60] K. Gomi, Y. Tang, V. Arbelaez, R. G. Crystal, and M. S. Walters, "Endothelial Cell Mediated Promotion of Ciliated Cell Differentiation of Human Airway Basal Cells via Insulin and Insulin-Like Growth Factor 1 Receptor Mediated Signaling," Stem Cell Reviews and Reports, vol. 13, no. 2, pp. 309-317, 2017.

[61] I. P. López, S. Piñeiro-Hermida, R. S. Pais, R. Torrens, A. Hoeflich, and J. G. Pichel, "Involvement of Igflr in bronchiolar epithelial regeneration: Role during repair kinetics after selective club cell ablation," PLoS ONE, vol. 11, no. 11, Article ID e0166388, 2016.

[62] A. Masood, M. Yi, M. Lau et al., "The IGF-I/IGF-R1 pathway regulates postnatal lung growth and is a nonspecific regulator of alveologenesis in the neonatal rat," American Journal of Physiology-Lung Cellular and Molecular Physiology, vol. 304, no. 9, pp. L626-L637, 2013.

[63] M. C. Ghosh, V. Gorantla, P. S. Makena et al., "Insulin-like growth factor-I stimulates differentiation of ATII cells to ATIlike cells through activation of Wnt5a," American Journal of Physiology-Lung Cellular and Molecular Physiology, vol. 305, no. 3, pp. L222-L228, 2013.

[64] T. A. Narasaraju, H. Chen, T. Weng et al., "Expression profile of IGF system during lung injury and recovery in rats exposed to hyperoxia: A possible role of IGF-1 in alveolar epithelial cell proliferation and differentiation," Journal of Cellular Biochemistry, vol. 97, no. 5, pp. 984-998, 2006.

[65] N. Moreno-Barriuso, A. V. López-Malpartida, F. De Pablo, and J. G. Pichel, "Alterations in alveolar epithelium differentiation and vasculogenesis in lungs of LIF/IGF-I double deficient embryos," Developmental Dynamics, vol. 235, no. 8, pp. 2040-2050, 2006.

[66] S. Srisuma, S. Bhattacharya, D. M. Simon et al., "Fibroblast growth factor receptors control epithelial-mesenchymal interactions necessary for alveolar elastogenesis," American Journal 
of Respiratory and Critical Care Medicine, vol. 181, no. 8, pp. 838$850,2010$.

[67] C. L. Day and R. M. Ryan, "Bronchopulmonary dysplasia: New becomes old again!”, Pediatric Research, vol. 81, no. 1-2, pp. 210213, 2017.

[68] E. Capoluongo, F. Ameglio, and C. Zuppi, "Insulin-like growth factor-I and complications of prematurity: A focus on bronchopulmonary dysplasia," Clinical Chemistry and Laboratory Medicine, vol. 46, no. 8, pp. 1061-1066, 2008.

[69] C. Löfqvist, G. Hellgren, A. Niklasson, E. Engström, D. Ley, and I. Hansen-Pupp, "Low postnatal serum IGF-I levels are associated with bronchopulmonary dysplasia (BPD)," Acta Paediatrica, vol. 101, no. 12, pp. 1211-1216, 2012.

[70] A. Hellström, E. Engström, A.-L. Hård et al., "Postnatal serum insulin-like growth factor i deficiency is associated with retinopathy of prematurity and other complications of premature birth," Pediatrics, vol. 112, no. 5, pp. 1016-1020, 2003.

[71] A. Chetty, S. Andersson, P. Lassus, and H. C. Nielsen, "InsulinLike Growth Factor-1 (IGF-1) and IGF-1 Receptor (IGF-1R) Expression in Human Lung in RDS and BPD," Pediatric Pulmonology, vol. 37, no. 2, pp. 128-136, 2004.

[72] E. Capoluongo, G. Vento, F. Ameglio et al., "Increased levels of IGF-1 and beta2-microglobulin in epithelial lining fluid of preterm newborns developing chronic lung disease: Effects of rhG-CSF," International Journal of Immunopathology and Pharmacology, vol. 19, no. 1, pp. 57-66, 2006.

[73] A. Chetty and H. C. Nielsen, "Regulation of cell proliferation by insulin-like growth factor 1 in hyperoxia-exposed neonatal rat lung," Molecular Genetics and Metabolism, vol. 75, no. 3, pp. 265-275, 2002.

[74] R. Belcastro, L. Lopez, J. Li, A. Masood, and A. K. Tanswell, "Chronic lung injury in the neonatal rat: Up-regulation of TGF $\beta 1$ and nitration of IGF-R1 by peroxynitrite as likely contributors to impaired alveologenesis," Free Radical Biology \& Medicine, vol. 80, pp. 1-11, 2015.

[75] T.-H. Kim, Y.-H. Chow, S. E. Gill, and L. M. Schnapp, "Effect of insulin-like growth factor blockade on hyperoxia-induced lung injury," American Journal of Respiratory Cell and Molecular Biology, vol. 47, no. 3, pp. 372-378, 2012.

[76] E. Capoluongo, F. Ameglio, P. Lulli et al., "Epithelial lining fluid free IGF-I-to-PAPP-A ratio is associated with bronchopulmonary dysplasia in preterm infants," American Journal of Physiology-Endocrinology and Metabolism, vol. 292, no. 1, pp. E308-E313, 2007.

[77] N. Olave, C. V. Lal, B. Halloran et al., "Regulation of alveolar septation by microRNA-489," American Journal of PhysiologyLung Cellular and Molecular Physiology, vol. 310, no. 5, pp. L476L487, 2016.

[78] Z. A. Jin, Z. Y. Jin, Y. X. Chi, and J. R. Lu, "Effects of recombinant human insulin-like growth factor-1 on the expression of Clara cell secretory protein in lung of hyperoxia-exposed newborn rats," Chinese Journal of Pediatrics, vol. 45, pp. 369-373, 2007.

[79] K. Ahamed, R. Epaud, M. Holzenberger et al., "Deficiency in type 1 insulin-like growth factor receptor in mice protects against oxygen-induced lung injury," Respiratory Research, vol. 6, no. 1, 2005.

[80] 2017, https:/clinicaltrials.gov/ct2/show/NCT01096784?term= NCT01096784\&rank=1.

[81] P. M. Krein and B. W. Winston, "Roles for insulin-like growth factor I and transforming growth factor- $\beta$ in fibrotic lung disease," CHEST, vol. 122, no. 6, supplement, pp. 289S-293S, 2002.
[82] J. Jagirdar, R. Begin, A. Dufresne, S. Goswami, T. C. Lee, and W. N. Rom, "Transforming growth factor-beta (TGF-beta) in silicosis," American Journal of Respiratory and Critical Care Medicine, vol. 154, no. 4, pp. 1076-1081, 1996.

[83] D. Vanhee, P. Gosset, B. Wallaert, C. Voisin, and A. B. Tonnel, "Mechanisms of fibrosis in coal workers' pneumoconiosis: Increased production of platelet-derived growth factor, insulinlike growth factor type I, and transforming growth factor $\beta$ and relationship to disease severity," American Journal of Respiratory and Critical Care Medicine, vol. 150, no. 4, pp. 1049-1055, 1994.

[84] M. H. Daba, K. E. El-Tahir, M. N. Al-Arifi, and O. A. Gubara, "Drug-induced pulmonary fibrosis," Saudi Medical Journal, vol. 25, no. 6, pp. 700-706, 2004.

[85] A. Emad and Y. Emad, "Levels of cytokine in bronchoalveolar lavage (BAL) fluid in patients with pulmonary fibrosis due to sulfur mustard gas inhalation," Journal of Interferon \& Cytokine Research, vol. 27, no. 1, pp. 38-43, 2007.

[86] N. K. Harrison, A. D. Cambrey, A. R. Myers et al., "Insulin-like growth factor-I is partially responsible for fibroblast proliferation induced by bronchoalveolar lavage fluid from patients with systemic sclerosis," Clinical Science, vol. 86, no. 2, pp. 141-148, 1994.

[87] Y. Hamaguchi, M. Fujimoto, T. Matsushita, M. Hasegawa, K. Takehara, and S. Sato, "Elevated serum insulin-like growth factor (IGF-1) and IGF binding protein-3 levels in patients with systemic sclerosis: possible role in development of fibrosis," The Journal of Rheumatology, vol. 35, no. 12, pp. 2363-2371, 2008.

[88] E. Hsu, H. Shi, R. M. Jordan, J. Lyons-Weiler, J. M. Pilewski, and C. A. Feghali-Bostwick, "Lung tissues in patients with systemic sclerosis have gene expression patterns unique to pulmonary fibrosis and pulmonary hypertension," Arthritis \& Rheumatology, vol. 63, no. 3, pp. 783-794, 2011.

[89] X. D. Jian, G. R. Guo, Y. J. Ruan, B. Zhao, Y. C. Wang, Q. Ning et al., "Clinical observation of rheumatoid arthritis associated interstitial lung disease patients and changes of serum cytokines thereof," National Medical Journal of China, vol. 88, pp. 18841887, 2008.

[90] A. Maeda, K. Hiyama, H. Yamakido, S. Ishioka, and M. Yamakido, "Increased expression of platelet-derived growth factor A and insulin-like growth factor-I in BAL cells during the development of bleomycin-induced pulmonary fibrosis in mice," CHEST, vol. 109, no. 3, pp. 780-786, 1996.

[91] X. Jian, M. Li, Y. Zhang et al., "Role of growth factors in acute lung injury induced by paraquat in a rat model," Human \& Experimental Toxicology, vol. 30, no. 6, pp. 460-469, 2011.

[92] S. C. Thornton, B. J. Walsh, S. Bennett et al., "Both in vitro and in vivo irradiation are associated with induction of macrophagederived fibroblast growth factors," Clinical \& Experimental Immunology, vol. 103, no. 1, pp. 67-73, 1996.

[93] C. A. Bloor, R. A. Knight, R. K. Kedia, M. A. Spiteri, and J. T. Allen, "Differential mRNA expression of insulin-like growth factor-1 splice variants in patients with idiopathic pulmonary fibrosis and pulmonary sarcoidosis," American Journal of Respiratory and Critical Care Medicine, vol. 164, no. 2, pp. 265-272, 2001.

[94] K. M. Antoniou, G. Soufla, R. Lymbouridou et al., "Expression analysis of angiogenic growth factors and biological axis CXCL12/CXCR4 axis in idiopathic pulmonary fibrosis," Connective Tissue Research, vol. 51, no. 1, pp. 71-80, 2010.

[95] S. Homma, I. Nagaoka, H. Abe et al., "Localization of plateletderived growth factor and insulin-like growth factor I in the 
fibrotic lung," American Journal of Respiratory and Critical Care Medicine, vol. 152, no. 6 I, pp. 2084-2089, 1995.

[96] S.-T. Uh, Y. Inoue, T. E. King Jr., E. D. Chan, L. S. Newman, and D. W. H. Riches, "Morphometric analysis of insulin-like growth factor-1 localization in lung tissues of patients with idiopathic pulmonary fibrosis," American Journal of Respiratory and Critical Care Medicine, vol. 158, no. 5, pp. 1626-1635, 1998.

[97] M. Selman, A. Pardo, and N. Kaminski, "Idiopathic pulmonary fibrosis: Aberrant recapitulation of developmental programs?" PLoS Medicine, vol. 5, no. 3, article no. e62, pp. 0373-0380, 2008.

[98] R. H. Goldstein, C. F. Poliks, P. F. Pilch, B. D. Smith, and A. Fine, "Stimulation of collagen formation by insulin and insulinlike growth factor I in cultures of human lung fibroblasts," Endocrinology, vol. 124, no. 2, pp. 964-970, 1989.

[99] M. Warnken, U. Reitzenstein, A. Sommer et al., "Characterization of proliferative effects of insulin, insulin analogues and insulin-like growth factor-1 (IGF-1) in human lung fibroblasts," Naunyn-Schmiedeberg's Archives of Pharmacology, vol. 382, no. 5-6, pp. 511-524, 2010.

[100] A. Chetty, S. Faber, and H. C. Nielsen, "Epithelial-mesenchymal interaction and insulin-like growth factors in hyperoxic lung injury," Experimental Lung Research, vol. 25, no. 8, pp. 701-718, 1999.

[101] A. Chetty, G.-J. Cao, and H. C. Nielsen, "Insulin-like growth factor-I signaling mechanisms, type I collagen and alpha smooth muscle actin in human fetal lung fibroblasts," Pediatric Research, vol. 60, no. 4, pp. 389-394, 2006.

[102] Y. Wu, M. Tewari, S. Cui, and R. Rubin, "Activation of the insulin-like growth factor-I receptor inhibits tumor necrosis factor-induced cell death," Journal of Cellular Physiology, vol. 168, no. 3, pp. 499-509, 1996.

[103] B. Valentinis, A. Morrione, F. Peruzzi, M. Prisco, K. Reiss, and R. Baserga, "Anti-apoptotic signaling of the IGF-I receptor in fibroblasts following loss of matrix adhesion," Oncogene, vol. 18, no. 10, pp. 1827-1836, 1999.

[104] J.-E. Choi, S.-S. Lee, D. A. Sunde et al., "Insulin-Like growth factor-i receptor blockade improves outcome in mouse model of lung injury," American Journal of Respiratory and Critical Care Medicine, vol. 179, no. 3, pp. 212-219, 2009.

[105] G. Kulik, A. Klippel, and M. J. Weber, "Antiapoptotic signalling by the insulin-like growth factor I receptor, phosphatidylinositol 3-kinase, and Akt," Molecular and Cellular Biology, vol. 17, no. 3, pp. 1595-1606, 1997.

[106] J. Dupont, S. E. Dunn, J. C. Barrett, and D. LeRoith, "Microarray Analysis and Identification of Novel Molecules Involved in Insulin-like Growth Factor-1 Receptor Signaling and Gene Expression," Recent Progress in Hormone Research, vol. 58, pp. 325-342, 2003.

[107] S. Li, J. Geng, X. Xu et al., "miR-130b-3p Modulates EpithelialMesenchymal Crosstalk in Lung Fibrosis by Targeting IGF-1," PLoS ONE, vol. 11, no. 3, p. e0150418, 2016.

[108] H. Li, I. S. Batth, X. Qu et al., "IGF-IR signaling in epithelial to mesenchymal transition and targeting IGF-IR therapy: Overview and new insights," Molecular Cancer, vol. 16, no. 1, article no. 6, 2017.

[109] L. K. Kotarkonda, R. Kulshrestha, and K. Ravi, "Role of insulin like growth factor axis in the bleomycin induced lung injury in rats," Experimental and Molecular Pathology, vol. 102, no. 1, pp. 86-96, 2017.

[110] S. Li, X. Xu, J. Geng, X. Huang, D. Jiang, and M. Zhu, "Role and underlying mechanism of IGF-I/ERK signaling pathway in lung fibrosis," Chinese Journal of Internal Medicine, vol. 95, pp. 16151618, 2015.

[111] C. G. T. Tahimic, R. K. Long, T. Kubota et al., "Regulation of ligand and shear stress-induced insulin-like growth factor 1 (IGF1) signaling by the integrin pathway," The Journal of Biological Chemistry, vol. 291, no. 15, pp. 8140-8149, 2016.

[112] D. Van Lonkhuyzen, B. Hollier, G. Shooter, D. Leavesley, and Z. Upton, "Chimeric vitronectin:insulin-like growth factor proteins enhance cell growth and migration through co-activation of receptors," Growth Factors, vol. 25, no. 5, pp. 295-308, 2007.

[113] L. Honeyman, M. Bazett, T. G. Tomko, and C. K. Haston, "MicroRNA profiling implicates the insulin-like growth factor pathway in bleomycin-induced pulmonary fibrosis in mice," Fibrogenesis \& Tissue Repair, vol. 6, no. 1, article no. 16, 2013.

[114] R. Eferl, P. Hasselblatt, M. Rath et al., "Development of pulmonary fibrosis through a pathway involving the transcription factor Fra-2/AP-1," Proceedings of the National Acadamy of Sciences of the United States of America, vol. 105, no. 30, pp. 10525-10530, 2008.

[115] J. M. Pilewski, L. Liu, A. C. Henry, A. V. Knauer, and C. A. Feghali-Bostwick, "Insulin-like growth factor binding proteins 3 and 5 are overexpressed in idiopathic pulmonary fibrosis and contribute to extracellular matrix deposition," The American Journal of Pathology, vol. 166, no. 2, pp. 399-407, 2005.

[116] J. Guiot, B. Bondue, M. Henket, J. L. Corhay, and R. Louis, "Raised serum levels of IGFBP-1 and IGFBP-2 in idiopathic pulmonary fibrosis," BMC Pulmonary Medicine, vol. 16, no. 1, article no. 86, 2016.

[117] K. L. Veraldi and C. A. Feghali-Bostwick, "Insulin-like growth factor binding proteins-3 and -5: Central mediators of fibrosis and promising new therapeutic targets," The Open Rheumatology Journal, vol. 6, no. 1, pp. 140-145, 2012.

[118] O. B. Mouhieddine, V. Cazals, E. Kuto, Y. Le Bouc, and A. Clement, "Glucocorticoid-induced growth arrest of lung alveolar epithelial cells is associated with increased production of insulin-like growth factor binding protein-2," Endocrinology, vol. 137, no. 1, pp. 287-295, 1996.

[119] J. Guiot, M. Henket, J. L. Corhay, C. Moermans, and R. Louis, "Sputum biomarkers in IPF: Evidence for raised gene expression and protein level of IGFBP-2, IL-8 and MMP-7," PLOS ONE, vol. 12, no. 2, Article ID e0171344, 2017.

[120] X. D. Ruiz, L. R. Mlakar, Y. Yamaguchi et al., "Syndecan-2 is a novel target of insulin-like growth factor binding protein-3 and is over-expressed in fibrosis," PLOS ONE, vol. 7, no. 8, Article ID e43049, 2012.

[121] M. Brissett, K. L. Veraldi, J. M. Pilewski, T. A. Medsger, and C. A. Feghali-Bostwick, "Localized expression of tenascin in systemic sclerosis-associated pulmonary fibrosis and its regulation by insulin-like growth factor binding protein 3," Arthritis \& Rheumatology, vol. 64, no. 1, pp. 272-280, 2012.

[122] H. Yasuoka, Z. Zhou, J. M. Pilewski, T. D. Oury, A. M. K. Choi, and C. A. Feghali-Bostwick, "Insulin-like growth factorbinding protein-5 induces pulmonary fibrosis and triggers mononuclear cellular infiltration," The American Journal of Pathology, vol. 169, no. 5, pp. 1633-1642, 2006.

[123] H. Yasuoka, E. Hsu, X. D. Ruiz, R. A. Steinman, A. M. K. Choi, and C. A. Feghali-Bostwick, "The fibrotic phenotype induced by IGFBP-5 is regulated by MAPK activation and Egr1-dependent and -independent mechanisms," The American Journal of Pathology, vol. 175, no. 2, pp. 605-615, 2009. 
[124] J. I. Jones, A. Gockerman, W. H. Busby Jr., C. Camacho-Hubner, and D. R. Clemmons, "Extracellular matrix contains insulinlike growth factor binding protein-5: Potentiation of the effects of IGF-I," The Journal of Cell Biology, vol. 121, no. 3, pp. 679-687, 1993.

[125] J. Beattie, G. J. Allan, J. D. Lochrie, and D. J. Flint, "Insulin-like growth factor-binding protein-5 (IGFBP-5): A critical member of the IGF axis," Biochemical Journal, vol. 395, no. 1, pp. 1-19, 2006.

[126] J. T. Allen, C. A. Bloor, R. A. Knight, and M. A. Spiteri, "Expression of insulin-like growth factor binding proteins in bronchoalveolar lavage fluid of patients with pulmonary sarcoidosis," American Journal of Respiratory Cell and Molecular Biology, vol. 19, no. 2, pp. 250-258, 1998.

[127] B. Melloni, O. Lesur, T. Bouhadiba, A. Cantin, M. Martel, and R. Bégin, "Effect of exposure to silica on human alveolar macrophages in supporting growth activity in type II epithelial cells," Thorax, vol. 51, no. 8, pp. 781-786, 1996.

[128] H. Olbrück, N. H. Seemayer, B. Voss, and M. Wilhelm, "Supernatants from quartz dust treated human macrophages stimulate cell proliferation of different human lung cells as well as collagen-synthesis of human diploid lung fibroblasts in vitro," Toxicology Letters, vol. 96-97, pp. 85-95, 1998.

[129] M. Griffin, R. Bhandari, G. Hamilton, Y.-C. Chan, and J. T. Powell, "Alveolar type II cell-fibroblast interactions, synthesis and secretion of surfactant and type I collagen," Journal of Cell Science, vol. 105, no. 2, pp. 423-432, 1993.

[130] A. L. Mora, E. Torres-González, M. Rojas et al., "Activation of alveolar macrophages via the alternative pathway in herpesvirus-induced lung fibrosis," American Journal of Respiratory Cell and Molecular Biology, vol. 35, no. 4, pp. 466-473, 2006.

[131] S. Gordon, "Alternative activation of macrophages," Nature Reviews Immunology, vol. 3, no. 1, pp. 23-35, 2003.

[132] D. Zhou, C. Huang, Z. Lin et al., "Macrophage polarization and function with emphasis on the evolving roles of coordinated regulation of cellular signaling pathways," Cellular Signalling, vol. 26, no. 2, pp. 192-197, 2014.

[133] P. J. Sime and K. M. A. O'Reilly, "Fibrosis of the lung and other tissues: new concepts in pathogenesis and treatment," Clinical Immunology, vol. 99, no. 3, pp. 308-319, 2001.

[134] W. N. Rom, P. Basset, G. A. Fells, T. Nukiwa, B. C. Trapnell, and R. G. Crystal, "Alveolar macrophages release an insulinlike growth factor I-type molecule," The Journal of Clinical Investigation, vol. 82, no. 5, pp. 1685-1693, 1988.

[135] W. N. Rom and P. Pääkkö, "Activated alveolar macrophages express the insulin-like growth factor-I receptor.", American Journal of Respiratory Cell and Molecular Biology, vol. 4, no. 5, pp. 432-439, 1991.

[136] S. Arkins, N. Rebeiz, D. L. Brunke-Reese, A. Biragyn, and K. W. Kelley, "Interferon-gamma inhibits macrophage insulin-like growth factor-I synthesis at the transcriptional level," Molecular Endocrinology, vol. 9, no. 3, pp. 350-360, 1995.

[137] M. W. Wynes and D. W. H. Riches, "Induction of macrophage insulin-like growth factor-I expression by the Th2 cytokines IL4 and IL-13," The Journal of Immunology, vol. 171, no. 7, pp. 35503559, 2003.

[138] M. W. Wynes, S. K. Frankel, and D. W. H. Riches, "IL4-induced macrophage-derived IGF-I protects myofibroblasts from apoptosis following growth factor withdrawal," Journal of Leukocyte Biology, vol. 76, no. 5, pp. 1019-1027, 2004.
[139] T. C. Haddad and C. A. Conover, "Insulin and interleukin-4 induce desensitization to the mitogenic effects of insulin-like growth factor-i: Pivotal role for insulin receptor substrate-2," The Journal of Biological Chemistry, vol. 272, no. 31, pp. 1952519531, 1997.

[140] W. Ruan and K. Ying, "Abnormal expression of IGF-binding proteins, an initiating event in idiopathic pulmonary fibrosis?" Pathology - Research and Practice, vol. 206, no. 8, pp. 537-543, 2010.

[141] C. Léger, A. Ni, G. Andonegui, J. Wong, C. Mowat, and B. W. Winston, "Adenovirus-mediated gene transfer of hIGF-IB in mouse lungs induced prolonged inflammation but no fibroproliferation," American Journal of Physiology-Lung Cellular and Molecular Physiology, vol. 298, no. 4, pp. L492-L500, 2010.

[142] S. K. Frankel, B. M. Moats-Staats, C. D. Cool, M. W. Wynes, A. D. Stiles, and D. W. H. Riches, "Human insulin-like growth factor-IA expression in transgenic mice promotes adenomatous hyperplasia but not pulmonary fibrosis," American Journal of Physiology-Lung Cellular and Molecular Physiology, vol. 288, no. 5, pp. L805-L812, 2005.

[143] G. Andonegui, A. Ni, C. Léger et al., "Sequential expression of IGF-IB followed by active TGF- $\beta 1$ induces synergistic pulmonary fibroproliferation in vivo," American Journal of Physiology-Lung Cellular and Molecular Physiology, vol. 303, no. 9, pp. L788-L798, 2012.

[144] A. Bitto, C. Lerner, C. Torres et al., "Long-term IGF-I exposure decreases autophagy and cell viability," PLoS ONE, vol. 5, no. 9, Article ID e12592, pp. 1-10, 2010.

[145] C. F. Hung, M. G. Rohani, S.-S. Lee, P. Chen, and L. M. Schnapp, "Role of IGF-1 pathway in lung fibroblast activation," Respiratory Research, vol. 14, no. 1, article 102, 2013.

[146] S. Piñeiro-Hermida, I. P. López, E. Alfaro-Arnedo et al., "IGF1R deficiency attenuates acute inflammatory response in a bleomycin-induced lung injury mouse model," Scientific Reports, vol. 7, no. 1, article no. 4290, 2017.

[147] V. M. Ranieri, G. D. Rubenfeld, B. T. Thompson et al., "Acute respiratory distress syndrome: the Berlin definition," The Journal of the American Medical Association, vol. 307, no. 23, pp. 25262533, 2012.

[148] P. M. Krein, P. J. B. Sabatini, W. Tinmouth, F. H. Y. Green, and B. W. Winston, "Localization of insulin-like growth factor-I in lung tissues of patients with fibroproliferative acute respiratory distress syndrome," American Journal of Respiratory and Critical Care Medicine, vol. 167, no. 1, pp. 83-90, 2003.

[149] G. Andonegui, P. M. Krein, C. Mowat et al., "Enhanced production of IGF-I in the lungs of fibroproliferative ARDS patients," Physiological Reports, vol. 2, no. 11, Article ID e12197, 2014.

[150] L. M. Schnapp, S. Donohoe, J. Chen et al., "Mining the acute respiratory distress syndrome proteome: Identification of the insulin-like growth factor (IGF)/IGF-binding protein-3 pathway in acute lung injury," The American Journal of Pathology, vol. 169, no. 1, pp. 86-95, 2006.

[151] A. M. Ahasic, P. Tejera, Y. Wei et al., "Predictors of circulating insulin-like growth factor-1 and insulin-like growth factorbinding protein-3 in critical illness," Critical Care Medicine, vol. 43, no. 12, pp. 2651-2659, 2015.

[152] A. M. Ahasic, R. Zhai, L. Su et al., "IGF1 and IGFBP3 in acute respiratory distress syndrome," European Journal of Endocrinology, vol. 166, no. 1, pp. 121-129, 2012. 
[153] C. Chen, L. Shi, Y. Li, X. Wang, and S. Yang, "Diseasespecific dynamic biomarkers selected by integrating inflammatory mediators with clinical informatics in ARDS patients with severe pneumonia," Cell Biology and Toxicology, vol. 32, no. 3, pp. 169-184, 2016.

[154] C. Müller, H. Wallaschofski, G. Brabant et al., "The association between IGF-I/IGFBP-3 and subclinical end points: Epidemiology faces the limits," The Journal of Clinical Endocrinology \& Metabolism, vol. 99, no. 8, pp. 2804-2812, 2014.

[155] H. S. Chand, Z. Woldegiorgis, K. Schwalm, J. McDonald, and Y. Tesfaigzi, "Acute inflammation induces insulin-like growth factor-1 to mediate Bcl-2 and Muc5ac expression in airway epithelial cells," American Journal of Respiratory Cell and Molecular Biology, vol. 47, no. 6, pp. 784-791, 2012.

[156] H. S. Chand, J. F. Harris, Y. Mebratu et al., "Intracellular insulin-like growth factor-1 induces Bcl-2 expression in airway epithelial cells," The Journal of Immunology, vol. 188, no. 9, pp. 4581-4589, 2012.

[157] M. A. Matthay, H. G. Folkesson, and C. Clerici, "Lung epithelial fluid transport and the resolution of pulmonary edema," Physiological Reviews, vol. 82, no. 3, pp. 569-600, 2002.

[158] S. Matalon, R. Bartoszewski, and J. F. Collawn, "Role of epithelial sodium channels in the regulation of lung fluid homeostasis," American Journal of Physiology-Lung Cellular and Molecular Physiology, vol. 309, no. 11, pp. L1229-L1238, 2015.

[159] M. A. Hussain, K. Studer, E. P. Messmer, and E. R. Froesch, "Treatment with insulin-like growth factor I alters capillary permeability in skin and retina," Diabetes, vol. 44, no. 10, pp. 1209-1212, 1995.

[160] S. Bake, A. K. Okoreeh, R. C. Alaniz, and F. Sohrabji, "InsulinLike Growth Factor (IGF)-I modulates endothelial bloodbrain barrier function in ischemic middle-aged female rats," Endocrinology, vol. 157, no. 1, pp. 61-69, 2016.

[161] M. Liang, L. E. Woodard, A. Liang et al., "Protective role of insulin-like growth factor-1 receptor in endothelial cells against unilateral ureteral obstruction - Induced renal fibrosis," The American Journal of Pathology, vol. 185, no. 5, article no. 1993, pp. 1234-1250, 2015.

[162] L. E. H. Smith, W. Shen, C. Perruzzi et al., "Regulation of vascular endothelial growth factor-dependent retinal neovascularization by insulin-like growth factor-1 receptor," Nature Medicine, vol. 5, no. 12, pp. 1390-1395, 1999.

[163] H. Imrie, H. Viswambharan, P. Sukumar et al., "Novel role of the IGF-1 receptor in endothelial function and repair: Studies in endothelium-targeted IGF-1 receptor transgenic mice," Diabetes, vol. 61, no. 9, pp. 2359-2368, 2012.

[164] V. Haurigot, P. Villacampa, A. Ribera et al., "Increased intraocular insulin-like growth factor-I triggers blood-retinal barrier breakdown," The Journal of Biological Chemistry, vol. 284, no. 34, pp. 22961-22969, 2009.

[165] F. Migneault, É. Boncoeur, F. Morneau, M. Pascariu, A. Dagenais, and Y. Berthiaume, "Cycloheximide and lipopolysaccharide downregulate $\alpha \mathrm{ENaC}$ mRNA via different mechanisms in alveolar epithelial cells," American Journal of Physiology-Lung Cellular and Molecular Physiology, vol. 305, no. 10, pp. L747L755, 2013.

[166] I.-H. Lee, A. Dinudom, A. Sanchez-Perez, S. Kumar, and D. I. Cook, "Akt mediates the effect of insulin on epithelial sodium channels by inhibiting Nedd4-2," The Journal of Biological Chemistry, vol. 282, no. 41, pp. 29866-29873, 2007.
[167] C. Mattes, M. Laube, and U. H. Thome, "Rapid elevation of sodium transport through insulin is mediated by AKT in alveolar cells," Physiological Reports, vol. 2, no. 3, p. e00269, 2014.

[168] B. Li, L. Chen, J. F. Ma, J. Zhao, M. Yin, R. G. Ding et al., "Protective effect of insulin-like growth factor-1 on acute lung injury induced by perfluoroisobutylene inhalation in mice," Chinese Journal of Critical Care Medicine, vol. 21, pp. 219-221, 2009.

[169] L. Ionescu, R. N. Byrne, T. van Haaften et al., "Stem cell conditioned medium improves acute lung injury in mice: in vivo evidence for stem cell paracrine action," American Journal of Physiology-Lung Cellular and Molecular Physiology, vol. 303, no. 11, pp. L967-L977, 2012.

[170] H. Lee, S. R. Kim, Y. Oh, S. H. Cho, R. P. Schleimer, and Y. C. Lee, "Targeting insulin-like growth factor-I and insulinlike growth factor-binding protein-3 signaling pathways: A novel therapeutic approach for asthma," American Journal of Respiratory Cell and Molecular Biology, vol. 50, no. 4, pp. 667677, 2014

[171] A. G. Hauache, A. Spinola-Castro, V. Lourenzi, S. Tufik, C. K. Naspitz, and D. Solé, "IGF-I, IGF-BP3, and GH Serum Levels after Stimulation Tests in Prepubertal Allergic Boys," Journal of Investigational Allergology and Clinical Immunology, vol. 13, no. 4, pp. 266-271, 2003.

[172] M. Hoshino, Y. Nakamura, J. J. Sim et al., "Inhaled corticosteroid reduced lamina reticularis of the basement membrane by modulation of insulin-like growth factor (IGF)-I expression in bronchial asthma," Clinical \& Experimental Allergy, vol. 28, no. 5, pp. 568-577, 1998.

[173] B. C. J. Van Der Eerden, M. Karperien, and J. M. Wit, "Systemic and Local Regulation of the Growth Plate," Endocrine Reviews, vol. 24, no. 6, pp. 782-801, 2003.

[174] J. Frystyk, A. J. Schou, C. Heuck et al., "Prednisolone reduces the ability of serum to activate the IGF1 receptor in vitro without affecting circulating total or free IGF1," European Journal of Endocrinology, vol. 168, no. 1, pp. 1-8, 2013.

[175] N. B. Gobbato, F. C. R. De Souza, S. B. N. Fumagalli et al., "Antileukotriene reverts the early effects of inflammatory response of distal parenchyma in experimental chronic allergic inflammation," BioMed Research International, vol. 2013, Article ID 523761, 2013.

[176] R. P. Vieira, R. A. Silva, M. C. Oliveira-Junior et al., "Exercise deactivates leukocytes in asthma," International Journal of Sports Medicine, vol. 35, no. 7, pp. 629-635, 2014.

[177] R. P. Vieira, V. F. De Andrade, A. C. S. Duarte et al., "Aerobic conditioning and allergic pulmonary inflammation in mice. II. Effects on lung vascular and parenchymal inflammation and remodeling," American Journal of Physiology-Lung Cellular and Molecular Physiology, vol. 295, no. 4, pp. L670-L679, 2008.

[178] R. P. Vieira, A. C. S. Duarte, R. C. Claudino et al., "Creatine supplementation exacerbates allergic lung inflammation and airway remodeling in mice," American Journal of Respiratory Cell and Molecular Biology, vol. 37, no. 6, pp. 660-667, 2007.

[179] S. C. Ferreira, A. C. Toledo, M. Hage et al., "Creatine activates airway epithelium in asthma," International Journal of Sports Medicine, vol. 31, no. 12, pp. 906-912, 2010.

[180] K. A. Drake, D. G. Torgerson, C. R. Gignoux, J. M. Galanter, L. A. Roth, and S. Huntsman, "A genome-wide association study of bronchodilator response in Latinos implicates rare variants," The Journal of Allergy and Clinical Immunology, vol. 133, pp. 370-378, 2014. 
[181] X. Yan, R. C. Baxter, and S. M. Firth, "Involvement of pregnancy-associated plasma protein-A2 in insulin-like growth factor (IGF) binding protein-5 proteolysis during pregnancy: A potential mechanism for increasing IGF bioavailability," The Journal of Clinical Endocrinology \& Metabolism, vol. 95, no. 3, pp. 1412-1420, 2010.

[182] M. Jaradat, C. Stapleton, S. L. Tilley et al., "Modulatory role for retinoid-related orphan receptor $\alpha$ in allergen-induced lung inflammation," American Journal of Respiratory and Critical Care Medicine, vol. 174, no. 12, pp. 1299-1309, 2006.

[183] T. L. Ediger and M. L. Toews, "Synergistic stimulation of airway smooth muscle cell mitogenesis," Journal of Pharmacology and Experimental Therapeutics, vol. 294, pp. 1076-1082, 2000.

[184] D. J. Lalor, B. Truong, S. Henness et al., "Mechanisms of serum potentiation of GM-CSF production by human airway smooth muscle cells," American Journal of Physiology-Lung Cellular and Molecular Physiology, vol. 287, no. 5, pp. L1007-L1016, 2004.

[185] V. Temkin and F. Levi-Schaffer, "Mechanism of tumour necrosis factor alpha mediated eosinophil survival," Cytokine, vol. 15, no. 1, pp. 20-26, 2001.

[186] J. P. Noveral, A. Bhala, R. L. Hintz, M. M. Grunstein, and P. Cohen, "Insulin-like growth factor axis in airway smooth muscle cells," American Journal of Physiology, vol. 267, no. 6, pp. L761-L765, 1994.

[187] P. Cohen, J. P. Noveral, A. Bhala, S. E. Nunn, D. J. Herrick, and M. M. Grunstein, "Leukotriene D4 facilitates airway smooth muscle cell proliferation via modulation of the IGF axis," American Journal of Physiology-Lung Cellular and Molecular Physiology, vol. 269, no. 2, pp. L151-L157, 1995.

[188] R. Gosens, D. Schaafsma, M. M. Grootte Bromhaar et al., "Growth factor-induced contraction of human bronchial smooth muscle is Rho-kinase-dependent," European Journal of Pharmacology, vol. 494, no. 1, pp. 73-76, 2004.

[189] R. Rajah, S. E. Nunn, D. J. Herrick, M. M. Grunstein, and P. Cohen, "Leukotriene D4 induces MMP-1, which functions as an IGFBP protease in human airway smooth muscle cells," American Journal of Physiology-Lung Cellular and Molecular Physiology, vol. 271, no. 6, pp. L1014-L1022, 1996.

[190] R. Rajah, R. V. Nachajon, M. H. Collins, H. Hakonarson, M. M. Grunstein, and P. Cohen, "Elevated levels of the IGF-binding protein protease MMP-1 in asthmatic airway smooth muscle," American Journal of Respiratory Cell and Molecular Biology, vol. 20, no. 2, pp. 199-208, 1999.

[191] G. Chen and N. Khalil, "TGF- $\beta 1$ increases proliferation of airway smooth muscle cells by phosphorylation of map kinases," Respiratory Research, vol. 7, article 2, 2006.

[192] P. Cohen, R. Rajah, J. Rosenbloom, and D. J. Herrick, "IGFBP-3 mediates TGF- $\beta 1$-induced cell growth in human airway smooth muscle cells," American Journal of Physiology-Lung Cellular and Molecular Physiology, vol. 278, no. 3, pp. L545-L551, 2000.

[193] C. Z. Han, I. J. Juncadella, J. M. Kinchen et al., "Macrophages redirect phagocytosis by non-professional phagocytes and influence inflammation," Nature, vol. 539, no. 7630, pp. 570-574, 2016.

[194] J. M. Garcia Pichel, S. Pineiro-Hermida, I. P. Lopez et al., "Attenuated airway hyperresponsiveness and mucus secretion in HDM exposed Igflr-deficient mice," in Proceedings of the ERS International Congress 2017 abstracts, p. PA4183.

[195] B. Ochensberger, G.-C. Daepp, S. Rihs, and C. A. Dahinden, "Human blood basophils produce interleukin-13 in response to IgE- receptor-dependent and -independent activation," Blood, vol. 88, no. 8, pp. 3028-3037, 1996.
[196] R. Koketsu, M. Suzukawa, A. Kawakami, A. Komiya, C. Ra, K. Yamamoto et al., "Activation of basophils by stem cell factor: comparison with insulin-like growth factor-I," J Investig Allergol Clin Immunol, vol. 18, pp. 293-299, 2008.

[197] A. Hartnell, A. Heinemann, D. M. Conroy et al., "Identification of selective basophil chemoattractants in human nasal polyps as insulin-like growth factor-1 and insulin-like growth factor2," The Journal of Immunology, vol. 173, no. 10, pp. 6448-6457, 2004.

[198] H. Kimata and M. Fujimoto, "Growth hormone and insullnlike growth factor i induce immunoglobulin (ig)e and igg4 production by human b cells," The Journal of Experimental Medicine, vol. 180, no. 2, pp. 727-732, 1994.

[199] J. H. Kim, H. H. Park, and C. E. Lee, "IGF-1 potentiation of IL4-induced CD23/Fc(epsilon)RII expression in human B cells," Mol Cells, vol. 15, pp. 307-312, 2003.

[200] X. J. Sun, L.-M. Wang, Y. Zhang et al., "Role of IRS-2 in insulin and cytokine signalling," Nature, vol. 377, no. 6545, pp. 173-177, 1995.

[201] J. A. Johnston, L.-M. Wang, E. P. Hanson et al., "Interleukins 2, 4, 7 , and 15 stimulate tyrosine phosphorylation of insulin receptor substrates 1 and 2 in T cells. Potential role of JAK kinases," The Journal of Biological Chemistry, vol. 270, no. 48, pp. 2852728530, 1995.

[202] H. Y. Wang, J. Zamorano, and A. D. Keegan, "A role for the insulin-interleukin (IL)- 4 receptor motif of the IL-4 receptor $\alpha$ chain in regulating activation of the insulin receptor substrate 2 and signal transducer and activator of transcription 6 pathways: Analysis by mutagenesis," The Journal of Biological Chemistry, vol. 273, no. 16, pp. 9898-9905, 1998.

[203] D. Bilbao, L. Luciani, B. Johannesson, A. Piszczek, and N. Rosenthal, "Insulin-like growth factor-1 stimulates regulatory T cells and suppresses autoimmune disease," EMBO Molecular Medicine, vol. 6, no. 11, pp. 1423-1435, 2005.

[204] Y. Pan, H. Liang, and H. Liu, "Platelet-secreted MicroRNA223 promotes endothelial cell apoptosis induced by advanced glycation end products via targeting the insulin-like growth factor 1 receptor," The Journal of Immunology, vol. 192, no. 1, pp. 437-446, 2014.

[205] X. Yao, W. Wang, Y. Li et al., "IL-25 induces airways angiogenesis and expression of multiple angiogenic factors in a murine asthma model," Respiratory Research, vol. 16, no. 1, 2015.

[206] S. Shan, Y. Li, J. Wang et al., "Nasal administration of interleukin-33 induces airways angiogenesis and expression of multiple angiogenic factors in a murine asthma surrogate," The Journal of Immunology, vol. 148, no. 1, pp. 83-91, 2016.

[207] M. Kawaguchi, J. Fujita, F. Kokubu et al., "Induction of insulinlike growth factor-I by interleukin-17F in bronchial epithelial cells," Clinical \& Experimental Allergy, vol. 40, no. 7, pp. 10361043, 2010.

[208] S. Zhang, H. Smartt, S. T. Holgate, and W. R. Roche, "Growth factors secreted by bronchial epithelial cells control myofibroblast proliferation: An in vitro co-culture model of airway remodeling in asthma," Laboratory Investigation, vol. 79, no. 4, pp. 395-405, 1999.

[209] S. Shoji, R. F. Ertl, J. Linder, S. Koizumi, W. C. Duckworth, and S. I. Rennard, "Bronchial epithelial cells respond to insulin and insulin-like growth factor-I as a chemoattractant." American Journal of Respiratory Cell and Molecular Biology, vol. 2, no. 6, pp. 553-557, 1990.

[210] L. Xu, X. Xiang, X. Ji et al., "Effects and mechanism of dehydroepiandrosterone on epithelial-mesenchymal transition 
in bronchial epithelial cells," Experimental Lung Research, vol. 40, no. 5, pp. 211-221, 2014.

[211] S. R. White, L. D. Martin, M. K. Abe, B. A. Marroquin, R. Stern, and X. Fu, "Insulin receptor substrate-1/2 mediates IL-4induced migration of human airway epithelial cells," American Journal of Physiology-Lung Cellular and Molecular Physiology, vol. 297, no. 1, pp. L164-L173, 2009.

[212] N. Yamashita, H. Tashimo, H. Ishida et al., "Role of insulin-like growth factor-I in allergen-induced airway inflammation and remodeling," Cellular Immunology, vol. 235, no. 2, pp. 85-91, 2005.

[213] S. R. Kim, K. S. Lee, K. B. Lee, and Y. C. Lee, "Recombinant IGFBP-3 inhibits allergic lung inflammation, VEGF production, and vascular leak in a mouse model of asthma," Allergy: European Journal of Allergy and Clinical Immunology, vol. 67, no. 7, pp. 869-877, 2012.

[214] K. L. Veraldi, B. T. Gibson, H. Yasuoka et al., "Role of insulin-like growth factor binding protein-3 in allergic airway remodeling," American Journal of Respiratory and Critical Care Medicine, vol. 180, no. 7, pp. 611-617, 2009.

[215] Y.-C. Lee, S. Jogie-Brahim, D.-Y. Lee et al., "Insulin-like growth factor-binding protein-3 (IGFBP-3) blocks the effects of asthma by negatively regulating NF- $\kappa \mathrm{B}$ signaling through IGFBP-3Rmediated activation of caspases," The Journal of Biological Chemistry, vol. 286, no. 20, pp. 17898-17909, 2011.

[216] K. S. Lee, S. J. Park, S. R. Kim et al., "Inhibition of VEGF blocks TGF- $\beta 1$ production through a PI3K/Akt signalling pathway," European Respiratory Journal, vol. 31, no. 3, pp. 523-531, 2008.

[217] P. J. Barnes, "Inflammatory mechanisms in patients with chronic obstructive pulmonary disease," The Journal of Allergy and Clinical Immunology, vol. 138, no. 1, pp. 16-27, 2016.

[218] K. Piehl-Aulin, I. Jones, B. Lindvall, A. Magnuson, and S. M. Abdel-Halim, "Increased serum inflammatory markers in the absence of clinical and skeletal muscle inflammation in patients with chronic obstructive pulmonary disease," Respiration, vol. 78, no. 2, pp. 191-196, 2009.

[219] M. Ye, H. Yu, W. Yu et al., "Evaluation of the significance of circulating insulin-like growth factor-1 and C-reactive protein in patients with chronic obstructive pulmonary disease," Journal of International Medical Research, vol. 40, no. 3, pp. 1025-1035, 2012.

[220] A. Hjalmarsen, U. Aasebø, K. Birkeland, G. Sager, and R. Jorde, "Impaired glucose tolerance in patients with chronic hypoxic pulmonary disease," Diabetes \& Metabolism, vol. 22, no. 1, pp. 37-42, 1996.

[221] F. Coşkun, E. Ege, E. Uzaslan, D. Ediger, M. Karadağ, and O. Gözü, "Evaluation of thyroid hormone levels and somatomedin-C (IGF-1) in patients with chronic obstructive pulmonary disease (COPD) and relation with the severity of the disease," Tüberküloz ve Toraks, vol. 57, no. 4, pp. 369-375, 2009.

[222] Ç. Öncel, S. Baser, M. Çam, B. Akda, B. Taspinar, and F. Evyapan, "Peripheral neuropathy in chronic obstructive pulmonary disease," COPD, vol. 7, no. 1, pp. 11-16, 2010.

[223] P. Kythreotis, A. Kokkini, S. Avgeropoulou et al., "Plasma leptin and insulin-like growth factor I levels during acute exacerbations of chronic obstructive pulmonary disease," $B M C$ Pulmonary Medicine, vol. 9, article 11, 2009.

[224] G. M. Corbo, A. Di Marco Berardino, A. Mancini et al., "Serum level of testosterone, dihydrotestosterone and IGF-1 during an Acute exacerbation of COPD and their relationships with inflammatory and prognostic indices: A pilot study," Minerva Medica, vol. 105, no. 4, pp. 289-294, 2014.
[225] M. J. Loza, R. Watt, F. Baribaud, E. S. Barnathan, and S. I. Rennard, "Systemic inflammatory profile and response to antitumor necrosis factor therapy in chronic obstructive pulmonary disease," Respiratory Research, vol. 13, article no. 12, 2012.

[226] C. A. Benbassat, D. D. Lazarus, S. B. Cichy et al., "Interleukin-1 $\alpha$ (IL- $1 \alpha)$ and tumor necrosis factor $\alpha$ (TNF $\alpha$ ) regulate insulinlike growth factor binding protein-1 (IGFBP-1) levels and mRNA abundance in vivo and in vitro," Hormone and Metabolic Research, vol. 31, no. 2-3, pp. 209-215, 1999.

[227] Z. Jiao, Q. Zhang, J. Chang et al., "A protective role of sulforaphane on alveolar epithelial cells exposed to cigarette smoke extract," Experimental Lung Research, vol. 39, no. 9, pp. 379-386, 2013.

[228] K.-C. Müller, L. Welker, K. Paasch et al., "Lung fibroblasts from patients with emphysema showmarkers of senescence in vitro," Respiratory Research, vol. 7, article no. 32, 2006.

[229] K.-C. Müller, K. Paasch, B. Feindt et al., "In contrast to lung fibroblasts - no signs of senescence in skin fibroblasts of patients with emphysema," Experimental Gerontology, vol. 43, no. 7, pp. 623-628, 2008.

[230] S. Goldstein, E. J. Moerman, R. A. Jones, and R. C. Baxter, "Insulin-like growth factor binding protein 3 accumulates to high levels in culture medium of senescent and quiescent human fibroblasts," Proceedings of the National Acadamy of Sciences of the United States of America, vol. 88, no. 21, pp. 96809684, 1991.

[231] H. R. Gosker, B. Kubat, G. Schaart, G. J. van der Vusse, E. F. M. Wouters, and A. M. W. J. Schols, "Myopathological features in skeletal muscle of patients with chronic obstructive pulmonary disease," European Respiratory Journal, vol. 22, no. 2, pp. 280285, 2003.

[232] E. Barreiro and J. Gea, "Respiratory and limb muscle dysfunction in COPD," COPD-Journal of Chronic Obstructive Pulmonary Disease, vol. 12, no. 4, pp. 413-426, 2015.

[233] A. Lewis, J. Riddoch-Contreras, S. A. Natanek et al., "Downregulation of the serum response factor/miR-1 axis in the quadriceps of patients with COPD," Thorax, vol. 67, no. 1, pp. 26-34, 2012.

[234] M. A. Spruit, R. Gosselink, T. Troosters et al., "Muscle force during an acute exacerbation in hospitalised patients with COPD and its relationship with CXCL8 and IGF-I," Thorax, vol. 58, no. 9, pp. 752-756, 2003.

[235] M. Fournier and M. I. Lewis, "Influences of IGF-I gene disruption on the cellular profile of the diaphragm," American Journal of Physiology-Endocrinology and Metabolism, vol. 278, no. 4, pp. E707-E715, 2000.

[236] T. Crul, M. A. Spruit, G. Gayan-Ramirez et al., "Markers of inflammation and disuse in vastus lateralis of chronic obstructive pulmonary disease patients," European Journal of Clinical Investigation, vol. 37, no. 11, pp. 897-904, 2007.

[237] R. Debigaré, K. Marquis, C. H. Côté et al., "Catabolic/anabolic balance and muscle wasting in patients with COPD," CHEST, vol. 124, no. 1, pp. 83-89, 2003.

[238] I. Vogiatzis, D. C. M. Simoes, G. Stratakos et al., "Effect of pulmonary rehabilitation on muscle remodelling in cachectic patients with COPD," European Respiratory Journal, vol. 36, no. 2, pp. 301-310, 2010.

[239] M. I. Lewis, M. Fournier, T. W. Storer et al., "Skeletal muscle adaptations to testosterone and resistance training in men with COPD," Journal of Applied Physiology, vol. 103, no. 4, pp. 12991310, 2007. 
[240] I. Vogiatzis, G. Stratakos, D. C. M. Simoes et al., "Effects of rehabilitative exercise on peripheral muscle TNF $\alpha$, IL-6, IGF-I and MyoD expression in patients with COPD," Thorax, vol. 62, no. 11, pp. 950-956, 2007.

[241] W. Mkacher, Z. Tabka, F. Chaieb et al., "Effect of rehabilitation program on endocrinological parameters in patients with COPD and in healthy subjects," COPD-Journal of Chronic Obstructive Pulmonary Disease, vol. 11, no. 6, pp. 681-688, 2014.

[242] Y. Kamiide, M. Furuya, N. Inomata, and T. Yada, "Chronic exposure to cigarette smoke causes extrapulmonary abnormalities in rats," Environmental Toxicology and Pharmacology, vol. 39, no. 2, pp. 864-870, 2015.

[243] M. J. Hansen, H. Chen, J. E. Jones et al., “The lung inflammation and skeletal muscle wasting induced by subchronic cigarette smoke exposure are not altered by a high-fat diet in mice," PLoS ONE, vol. 8, no. 11, Article ID e80471, 2013.

[244] M. Fournier, Z. Huang, H. Li, X. Da, B. Cercek, and M. I. Lewis, "Insulin-like growth factor I prevents corticosteroidinduced diaphragm muscle atrophy in emphysematous hamsters," American Journal of Physiology-Regulatory, Integrative and Comparative Physiology, vol. 285, no. 1, pp. R34-R43, 2003.

[245] M. I. Lewis, A. T. Feinberg, and M. Fournier, "IGF-I and/or growth hormone preserve diaphragm fiber size with moderate malnutrition," Journal of Applied Physiology, vol. 85, no. 1, pp. 189-197, 1998.

[246] Y. Iioka, K. Tatsumi, K. Sugito, T. Moriya, and T. Kuriyama, "Effects of insulin-like growth factor on nitrogen balance during hypoxic exposure," European Respiratory Journal, vol. 20, no. 2, pp. 293-299, 2002.

[247] Y. Iioka, K. Tatsumi, K. Sugito, T. Moriya, and T. Kuriyama, "Effects of insulin-like growth factor on weight gain in chronic hypoxic rats," Journal of Cardiovascular Pharmacology, vol. 39, no. 5, pp. 636-642, 2002.

[248] A. H. V. Remels, H. R. Gosker, R. C. J. Langen, and A. M. W. J. Schols, "The mechanisms of cachexia underlying muscle dysfunction in COPD," Journal of Applied Physiology, vol. 114, no. 9, pp. 1253-1262, 2013.

[249] M. Barbieri, M. Bonafè, C. Franceschi, and G. Paolisso, "Insulin/ IGF-I-signaling pathway: an evolutionarily conserved mechanism of longevity from yeast to humans," American Journal of Physiology-Endocrinology and Metabolism, vol. 285, no. 5, pp. E1064-E1071, 2003.

[250] A. Richardson, F. Liu, M. L. Adamo, H. Van Remmen, and J. F. Nelson, "The role of insulin and insulin-like growth factorI in mammalian ageing," Best Practice \& Research Clinical Endocrinology \& Metabolism, vol. 18, no. 3, pp. 393-406, 2004.

[251] N. Mercado, K. Ito, and P. J. Barnes, "Accelerated ageing of the lung in COPD: new concepts," Thorax, vol. 70, no. 5, pp. 482489, 2015.

[252] M. Holzenberger, J. Dupont, B. Ducos et al., "IGF-1 receptor regulates lifespan and resistance to oxidative stress in mice," Nature, vol. 421, no. 6919, pp. 182-187, 2003.

[253] A. Podlutsky, M. N. Valcarcel-Ares, K. Yancey et al., “The GH/ IGF-1 axis in a critical period early in life determines cellular DNA repair capacity by altering transcriptional regulation of DNA repair-related genes: implications for the developmental origins of cancer," GeroScience, vol. 39, no. 2, pp. 147-160, 2017.

[254] N. Takasaka, J. Araya, H. Hara et al., "Autophagy induction by SIRT6 through attenuation of insulin-like growth factor signaling is involved in the regulation of human bronchial epithelial cell senescence," The Journal of Immunology, vol. 192, no. 3, pp. 958-968, 2014.
[255] K. Ito, T. Colley, and N. Mercado, "Geroprotectors as a novel therapeutic strategy for COPD, an accelerating aging disease," International Journal of Chronic Obstructive Pulmonary Disease, vol. 7, pp. 641-652, 2012.

[256] P. J. Barnes, "Identifying Molecular Targets for New Drug Development for Chronic Obstructive Pulmonary Disease: What Does the Future Hold?" Seminars in Respiratory and Critical Care Medicine, vol. 36, no. 4, Article ID 01131, pp. 508522, 2015.

[257] M. Cohen-Cymberknoh, E. Kerem, T. Ferkol, and A. Elizur, "Airway inflammation in cystic fibrosis: molecular mechanisms and clinical implications," Thorax, vol. 68, no. 12, pp. 1157-1162, 2013.

[258] A. H. Gifford, A. B. Nymon, and A. Ashare, "Serum insulinlike growth factor-1 (IGF-1) during CF pulmonary exacerbation: Trends and biomarker correlations," Pediatric Pulmonology, vol. 49, no. 4, pp. 335-341, 2014.

[259] M. Ulrich, D. Worlitzsch, S. Viglio et al., "Alveolar inflammation in cystic fibrosis," Journal of Cystic Fibrosis, vol. 9, no. 3, pp. 217227, 2010.

[260] J. L. Bessich, A. B. Nymon, L. A. Moulton, D. Dorman, and A. Ashare, "Low levels of insulin-like growth factor-1 contribute to alveolar macrophage dysfunction in cystic fibrosis," The Journal of Immunology, vol. 191, no. 1, pp. 378-385, 2013.

[261] M. E. Street, M. A. Ziveri, C. Spaggiari et al., "Inflammation is a modulator of the insulin-like growth factor (IGF)/IGF-binding protein system inducing reduced bioactivity of IGFs in cystic fibrosis," European Journal of Endocrinology, vol. 154, no. 1, pp. 47-52, 2006.

[262] M. P. Rogan, L. R. Reznikov, A. A. Pezzulo et al., "Pigs and humans with cystic fibrosis have reduced insulin-like growth factor 1 (IGF1) levels at birth," Proceedings of the National Acadamy of Sciences of the United States of America, vol. 107, no. 47, pp. 20571-20575, 2010.

[263] L. A. Rosenberg, M. D. Schluchter, A. F. Parlow, and M. L. Drumm, "Mouse as a model of growth retardation in cystic fibrosis," Pediatric Research, vol. 59, no. 2, pp. 191-195, 2006.

[264] J. Lebl, M. Zahradníková, J. Bartošová, D. Zemková, M. Pechová, and V. Vávrová, "Insulin-like growth factor-I and insulin-like growth factor-binding protein-3 in cystic fibrosis: A positive effect of antibiotic therapy and hyperalimentation," Acta Paediatrica, vol. 90, no. 8, pp. 868-872, 2001.

[265] M. E. Street, C. Spaggiari, C. Volta et al., "The IGF system and cytokine interactions and relationships with longitudinal growth in prepubertal patients with cystic fibrosis," Clinical Endocrinology, vol. 70, no. 4, pp. 593-598, 2009.

[266] M. Switzer, J. Rice, M. Rice, and D. S. Hardin, "Insulinlike growth factor-I levels predict weight, height and protein catabolism in children and adolescents with cystic fibrosis," Journal of Pediatric Endocrinology and Metabolism, vol. 22, no. 5, pp. 417-424, 2009.

[267] M. E. Haupt, E. E. Kim, and A. L. Prestridge, "Successful prolonged use of recombinant human insulin-like growth factor-1 in a child with cystic fibrosis," Pediatric Pulmonology, vol. 46, no. 11, pp. 1137-1141, 2011.

[268] 2017, https://clinicaltrials.gov/ct2/show/NCT00566241?term= IGF-1\&cond=Lung+Diseases\&draw $=1 \&$ rank=3.

[269] S. Novello, G. Scagliotti, G. de Castro et al., "An Open-Label, Multicenter, Randomized, Phase II Study of Cisplatin and Pemetrexed With or Without Cixutumumab (IMC-A12) as a First-Line Therapy in Patients With Advanced Nonsquamous 
Non-Small Cell Lung Cancer," Journal of Thoracic Oncology, vol. 12, no. 2, pp. 383-389, 2017.

[270] S. M. Rowe, S. Miller, and E. J. Sorscher, "Cystic fibrosis," The New England Journal of Medicine, vol. 352, no. 19, pp. 1992-2001, 2005.

[271] B. S. Zemel, A. F. Jawad, S. FitzSimmons, and V. A. Stallings, "Longitudinal relationship among growth, nutritional status, and pulmonary function in children with cystic fibrosis: Analysis of the Cystic Fibrosis Foundation National CF Patient Registry," Journal of Pediatrics, vol. 137, no. 3, pp. 374-380, 2000.

[272] S. M. Blackman and V. Tangpricha, "Endocrine Disorders in Cystic Fibrosis," Pediatric Clinics of North America, vol. 63, no. 4, pp. 699-708, 2016.

[273] E. Mosfeldt Laursen, A. Juul, S. Lanng et al., "Diminished concentrations of insulin-like growth factor I in cystic fibrosis," Archives of Disease in Childhood, vol. 72, no. 6, pp. 494-497, 1995.

[274] C. N. Falany, D. He, L. Li et al., "Regulation of hepatic sulfotransferase (SULT) 1E1 expression and effects on estrogenic activity in cystic fibrosis (CF)," The Journal of Steroid Biochemistry and Molecular Biology, vol. 114, no. 1-2, pp. 113-119, 2009.

[275] L. Li, D. He, T. W. Wilborn, J. L. Falany, and C. N. Falany, "Increased SULT1E1 activity in HepG2 hepatocytes decreases growth hormone stimulation of STAT5b phosphorylation," Steroids, vol. 74, no. 1, pp. 20-29, 2009.

[276] H. W. Lee, J. Cheng, O. Kovbasnjuk, M. Donowitz, and W. B. Guggino, "Insulin-Like Growth Factor 1 (IGF-1) Enhances the Protein Expression of CFTR," PLOS ONE, vol. 8, no. 3, Article ID e59992, 2013.

[277] J. Cheng, H. Wang, and W. B. Guggino, "Regulation of cystic fibrosis transmembrane regulator trafficking and protein expression by a rho family small GTPase TC10," The Journal of Biological Chemistry, vol. 280, no. 5, pp. 3731-3739, 2005.

[278] M. Ozen, H. Cokugras, N. Ozen, Y. Camcioglu, and N. Akcakaya, "Relation between serum insulin-like growth factorI and insulin-like growth factor-binding protein-3 levels, clinical status and growth parameters in prepubertal cystic fibrosis patients," Pediatrics International, vol. 46, no. 4, pp. 429-435, 2004.

[279] E. M. Laursen, S. Lanng, M. H. Rasmussen, C. Koch, N. E. Skakkebæk, and J. Müller, "Normal spontaneous and stimulated $\mathrm{GH}$ levels despite decreased IGF-I concentrations in cystic fibrosis patients," European Journal of Endocrinology, vol. 140, no. 4, pp. 315-321, 1999.

[280] A. M. Taylor, A. Bush, A. Thomson et al., "Relation between insulin-like growth factor-I, body mass index, and clinical status in cystic fibrosis," Archives of Disease in Childhood, vol. 76, no. 4, pp. 304-309, 1997.

[281] A. M. Taylor, A. Thomson, C. Bruce-Morgan et al., "The relationship between insulin, IGF-I and weight gain in cystic fibrosis," Clinical Endocrinology, vol. 51, no. 5, pp. 659-665, 1999.

[282] P. Ripa, I. Robertson, D. Cowley, M. Harris, I. Brent Masters, and A. M. Cotterill, "The relationship between insulin secretion, the insulin-like growth factor axis and growth in children with cystic fibrosis," Clinical Endocrinology, vol. 56, no. 3, pp. 383389, 2002.

[283] J. C. Canale-Zambrano and C. K. Haston, "IGF binding protein3 treatment alters intestinal cell proliferation but not body weight of adult cystic fibrosis transmembrane conductance regulator deficient mice," Pediatric Research, vol. 69, no. 2, pp. 129-134, 2011.
[284] A. Smerieri, L. Montanini, L. Maiuri, S. Bernasconi, and M. E. Street, "FOXO1 content is reduced in cystic fibrosis and increases with IGF-I treatment," International Journal of Molecular Sciences, vol. 15, no. 10, pp. 18000-18022, 2014.

[285] D. Schnabel, C. Grasemann, D. Staab, H. Wollmann, and F. Ratjen, "A multicenter, randomized, double-blind, placebocontrolled trial to evaluate the metabolic and respiratory effects of growth hormone in children with cystic fibrosis," Pediatrics, vol. 119, no. 6, pp. e1230-e1238, 2007.

[286] V. Thaker, A. L. Haagensen, B. Carter, Z. Fedorowicz, and B. W. Houston, "Recombinant growth hormone therapy for cystic fibrosis in children and young adults," Cochrane Database of Systematic Reviews, vol. 5, p. CD008901, 2015.

[287] J. C. Bucuvalas, S. D. Chernausek, M. P. Alfaro, S. K. Krug, W. Ritschel, and R. W. Wilmott, "Effect of insulinlike growth factor1 treatment in children with cystic fibrosis," Journal of Pediatric Gastroenterology and Nutrition, vol. 33, no. 5, pp. 576-581, 2001.

[288] S. C. Wong, R. Dobie, M. A. Altowati, G. A. Werther, C. Farquharson, and S. F. Ahmed, "Growth and the growth hormone-insulin like growth factor 1 axis in children with chronic inflammation: Current Evidence, Gaps in Knowledge, and Future Directions," Endocrine Reviews, vol. 37, no. 1, pp. 62$110,2016$.

[289] A. L. Rosenbloom, "Mecasermin (recombinant human insulinlike growth factor I)," Advances in Therapy, vol. 26, no. 1, pp. 40-54, 2009.

[290] G. B. Camilo, F. S. Guimarães, D. P. G. Silva et al., "Pulmonary function testing and chest tomography in patients with acromegaly," Multidisciplinary Respiratory Medicine, vol. 8, no. 1, article no. 70, 2013.

[291] U. Koser and A. Hill, "What's new in the management of adult bronchiectasis?” F1000Research, vol. 6, article no. 527, 2017.

[292] "Retraction: Molecular Analysis of Non-Small Cell Lung Cancer Identifies Subsets with Different Sensitivity to Insulin-like Growth Factor I Receptor Inhibition," Clinical Cancer Research, vol. 20, no. 12, pp. 3358-3358, 2014. 


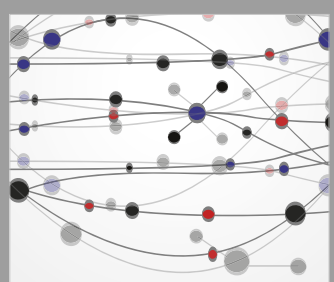

The Scientific World Journal
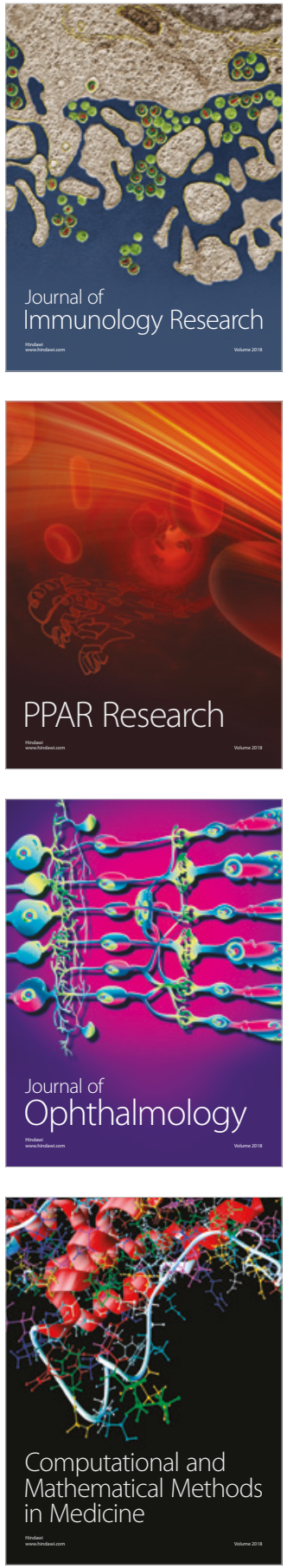

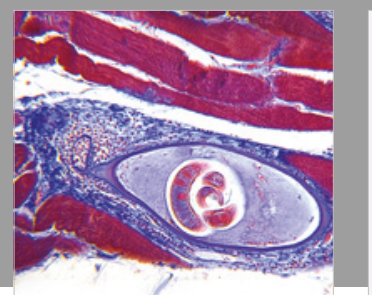

Gastroenterology Research and Practice

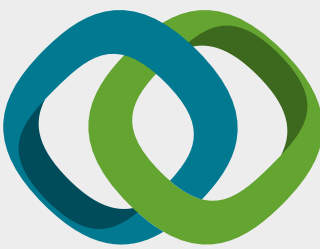

\section{Hindawi}

Submit your manuscripts at

www.hindawi.com
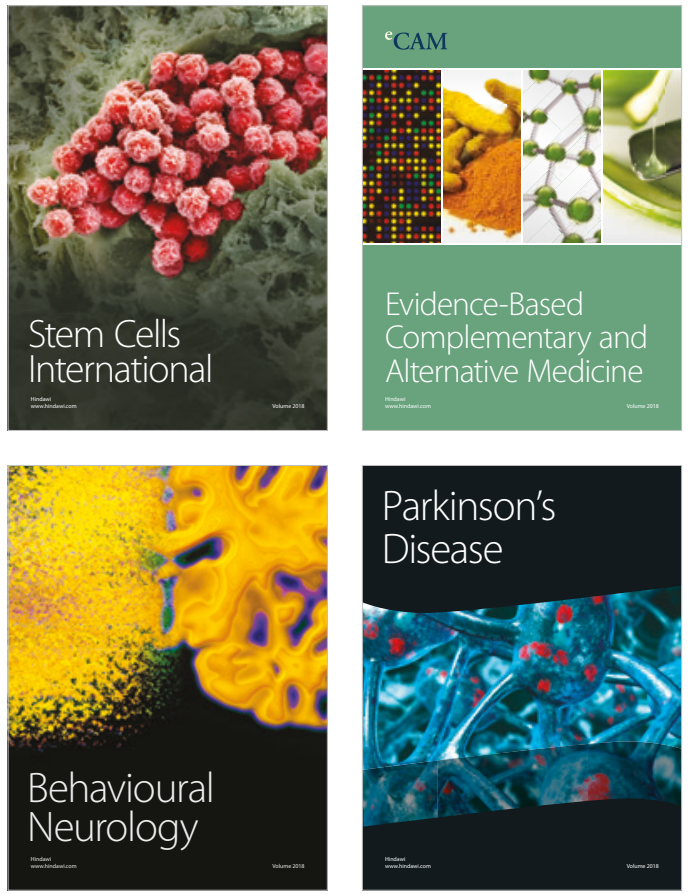

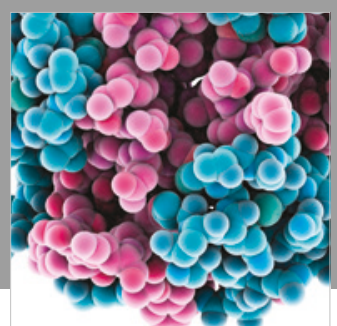

ournal of

Diabetes Research

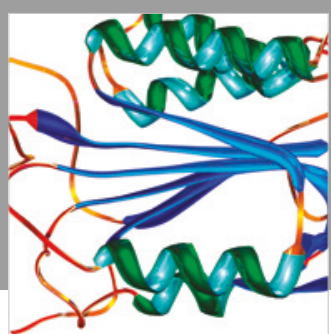

Disease Markers
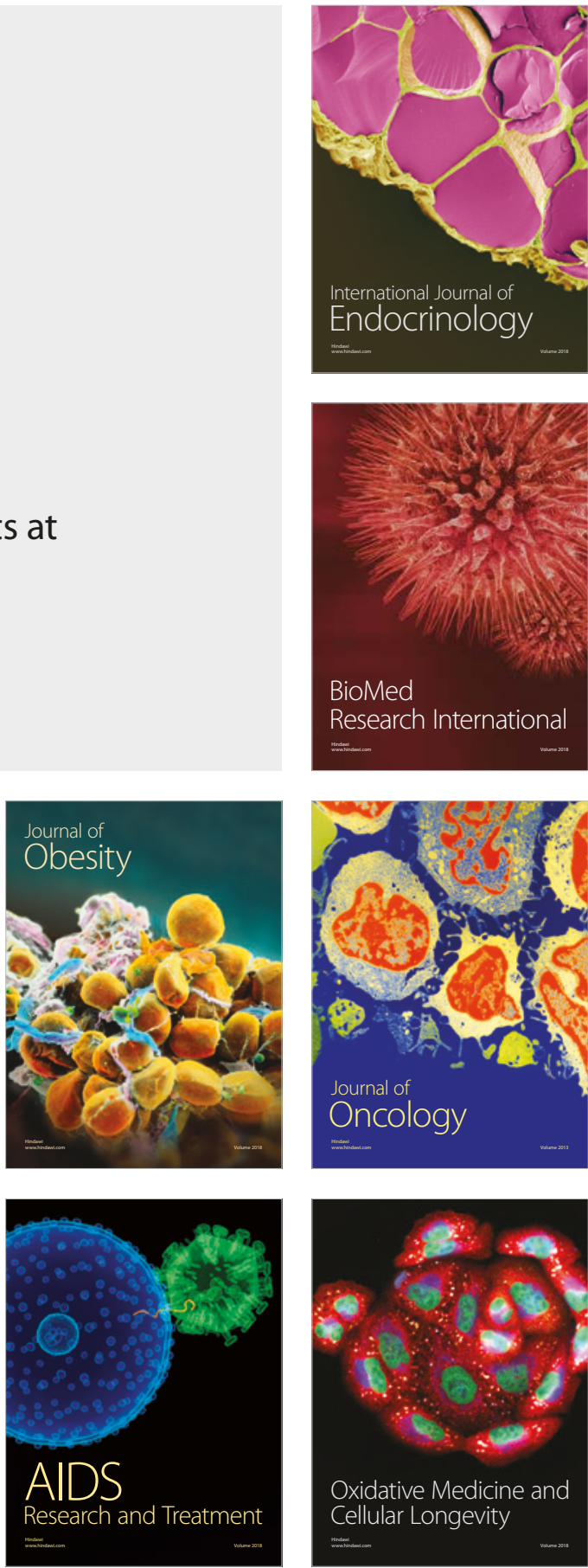